\title{
Systematic study on the influence of the morphology of -MoO3 in the selective oxidation of propylene
}

Schuh, Kirsten; Kleist, Wolfgang; Høj, Martin; Jensen, Anker Degn; Beato, Pablo; Patzke, Greta R.; Grunwaldt, Jan-Dierk

Published in:

Journal of Solid State Chemistry

Link to article, DOI:

10.1016/j.jssc.2015.04.011

Publication date:

2015

Document Version

Peer reviewed version

Link back to DTU Orbit

Citation (APA):

Schuh, K., Kleist, W., Høj, M., Jensen, A. D., Beato, P., Patzke, G. R., \& Grunwaldt, J-D. (2015). Systematic study on the influence of the morphology of -MoO3 in the selective oxidation of propylene. Journal of Solid State Chemistry, 228, 42-52. https://doi.org/10.1016/j.jssc.2015.04.011

\section{General rights}

Copyright and moral rights for the publications made accessible in the public portal are retained by the authors and/or other copyright owners and it is a condition of accessing publications that users recognise and abide by the legal requirements associated with these rights.

- Users may download and print one copy of any publication from the public portal for the purpose of private study or research.

- You may not further distribute the material or use it for any profit-making activity or commercial gain

- You may freely distribute the URL identifying the publication in the public portal 


\title{
Systematic study on the influence of the morphology of $\alpha-\mathrm{MoO}_{3}$ in the selective oxidation of propylene
}

Kirsten Schuh, Wolfgang Kleist, Martin Høj, Anker Degn Jensen, Pablo Beato, Greta R. Patzke and Jan-Dierk Grunwaldt*

Authors and Corresponding Author*

Kirsten Schuh, Dr. Wolfgang Kleist, Prof. Dr. Jan-Dierk Grunwaldt*

Karlsruhe Institute of Technology (KIT), Institute for Chemical Technology and Polymer Chemistry (ITCP) and Institute of Catalysis Research and Technology (IKFT), Engesserstr. 20, 76131 Karlsruhe (Germany)

E-Mail: grunwaldt@kit.edu

Telephone: +4972160842120

Dr. Martin Høj, Prof. Dr. Anker Degn Jensen

Technical University of Denmark (DTU), Department of Chemical \& Biochemical

Engineering, Søltofts Plads, DK-2800 Kgs. Lyngby (Denmark)

Prof. Dr. Greta R. Patzke

University of Zurich (UZH), Institute of Inorganic Chemistry, Winterthurerstrasse 190, CH-

8057 Zurich (Switzerland)

Dr. Pablo Beato

Haldor Topsøe A/S, Nymøllevej 55, DK-2800 Kgs. Lyngby (Denmark)

Keywords: Propylene Oxidation; Molybdenum oxides; Hydrothermal Synthesis; Structure Sensitivity; Morphology

\begin{abstract}
A variety of morphologically different $\alpha-\mathrm{MoO}_{3}$ samples were prepared by hydrothermal synthesis and applied in the selective oxidation of propylene. Their catalytic performance was compared to $\alpha-\mathrm{MoO}_{3}$ prepared by flame spray pyrolysis (FSP) and a classical synthesis route. Hydrothermal synthesis from ammonium heptamolybdate (AHM) and nitric acid at $\mathrm{pH} 1-2$ led to ammonium containing molybdenum oxide phases that were completely transformed into $\alpha-\mathrm{MoO}_{3}$ after calcination at $550{ }^{\circ} \mathrm{C}$. A one-step synthesis of $\alpha-\mathrm{MoO}_{3}$ rods was possible starting from $\mathrm{MoO}_{3} \cdot 2 \mathrm{H}_{2} \mathrm{O}$ with acetic acid or nitric acid and from AHM with nitric acid at $180{ }^{\circ} \mathrm{C}$. Particularly, if nitric acid was used during synthesis, the rod-like morphology of the samples could be stabilized during calcination at $550{ }^{\circ} \mathrm{C}$ and following catalytic activity tests, which was beneficial for the catalytic performance in propylene oxidation. Characterization studies using X-ray diffraction (XRD), scanning electron microscopy (SEM) and Raman spectroscopy showed that those samples, which retained their rod-like morphology during the activity tests, yielded the highest propylene conversion.
\end{abstract}




\section{Introduction}

Beside chemical composition and crystal structure of transition metal oxides especially their morphology and particle size strongly influence their performance in catalytic reactions. Their influence on catalytic activity and selectivity was demonstrated in a number of studies, e.g., for $\mathrm{CeO}_{2}$ [1, 2], $\mathrm{Cu}_{2} \mathrm{O}$ [3], $\mathrm{Fe}_{2} \mathrm{O}_{3}$ [4] or $\mathrm{Co}_{3} \mathrm{O}_{4}$ [5]. Especially selective oxidation reactions are known to be structure sensitive and thus strongly dependent on the shape [6-9]. Therefore the ability to control particle size, shape and composition of transition metal oxides has become an important research topic [10-13]

Hydrothermal synthesis is an ideal method to obtain transition metal oxides of controlled morphology, high crystallinity and narrow particle size distribution with good reproducibility [14]. A number of synthesis parameters such as the $\mathrm{pH}$ value of the reaction medium, reaction temperature or addition of structure directing agents can be used to tune the crystalline phases and the morphology [15]. Although hydrothermal synthesis is a rather facile method for the preparation of solid materials it has apart from zeolite synthesis rarely been used for catalyst preparation. The method is, however, particularly attractive for (mixed) molybdenum oxides, which have high potential as catalysts in the selective oxidation of hydrocarbons [17-22]. Various preparation routes are known for the hydrothermal synthesis of molybdenum trioxide in the shape of ribbons, rods or nanobelts [12, 23-28]. These $\mathrm{MoO}_{3}$ nanomaterials tolerate temperatures up to $400{ }^{\circ} \mathrm{C}$ [12]. Furthermore, the crystal morphology can be altered by using different inorganic salts like $\mathrm{NaNO}_{3}$ and $\mathrm{KNO}_{3}$ in the synthesis solution [23, 24]. However, they have been hardly tested in catalysis and the use of inorganic salts or hydrochloric acid may have a negative influence on the catalytic activity of the synthesized molybdenum oxides due to potential sodium, potassium, or chlorine residues in the product.

For the design of molybdenum trioxide model catalysts the formation of both the thermodynamically stable orthorhombic $\alpha-\mathrm{MoO}_{3}$ and the metastable monoclinic $\beta-\mathrm{MoO}_{3}$ with $\mathrm{ReO}_{3}$-type structure need to be considered. $\alpha-\mathrm{MoO}_{3}$ is particularly interesting due to its intrinsic structural anisotropy considering that asymmetric $\mathrm{MoO}_{6}$ octahedra, which are interconnected via corner linking along the [100] direction and edge sharing along the [001] direction, form double layers within the (010) plane. Alternating stacks of these layered sheets bound by van der Waal interactions lead to the anisotropic structure of 
orthorhombic $\alpha-\mathrm{MoO}_{3}[23,27,29,30]$. This structural anisotropy has been used to tune its catalytic properties and especially the selectivity in oxidation reactions, because the different crystal facets favor different reaction mechanisms. $\mathrm{MoO}_{3}$ is thus since long time known as a structure sensitive catalyst e.g. in the oxidation of olefins $[8,20,31,32]$ and alcohols $[9,33,34]$ as well as the reduction of $\mathrm{NO}_{\mathrm{x}}$ [35]. Hernandez and Ozkan [36] tested the structural specificity of orthorhombic $\mathrm{MoO}_{3}$ in the oxidation of 1-butene, 1,3-butadiene, furan and maleic acid. They found that a sample prepared by temperature-programmed calcination up to $600{ }^{\circ} \mathrm{C}$, which contained a lower ratio of the basal (010) facet compared to edge planes (100), was more active in partial oxidation. A higher (010)/(100) ratio in a more ribbon like sample, which was obtained at $795{ }^{\circ} \mathrm{C}$ and quench cooling, led to total oxidation. Volta and coworkers $[8,31,32]$ applied graphite supported $\mathrm{MoO}_{3}$ prepared from $\mathrm{MoCl}_{5}$ at different temperatures as a catalyst in the oxidation of propylene and claimed the (100) plane to be active for acrolein formation and the (010) plane for $\mathrm{CO}_{2}$ production. Testing the catalytic performance of oxidized Mo foils in the oxidation of propylene confirmed that total oxidation occurred on the basal (010) planes. [37, 38] In contrast, Ziolkowski [39] concluded from a theoretical study applying a bond strength model that acrolein can be formed on (101) facets containing isolated active oxygen e.g. adsorbed oxygen or lattice oxygen with a relatively long bond with molybdenum. When the adsorption site for propylene (Mo) is surrounded by several active lattice oxygen atoms and adsorbed oxygen atoms, e.g. on the (001) or (100) facets, further oxidation or undesired total combustion occurred, respectively. Brïckman et al. [20] claimed the (100) and (101) facets to be responsible for the activation of propylene, while oxygen was subsequently inserted into activated propylene on the (010) facet. Haber and Serwicka [40] came to the same conclusion that more acrolein was formed on orthorhombic $\mathrm{MoO}_{3}$ with a relatively high surface area of the (010) facet and that the activation of propylene occurred on the side facets.

Hence, we aim in the present study at the design of morphologically different transition metal oxide materials using hydrothermal synthesis and only slightly varying reaction conditions. As a rather simple system, we synthesized hydrothermally $\alpha-\mathrm{MoO}_{3}$ with different morphology using e.g. different precursors, acids and $\mathrm{pH}$ values. For comparison a high surface area $\alpha-\mathrm{MoO}_{3}$ was prepared by onestep flame spray pyrolysis [41]. All samples were calcined under the same conditions to exclude a 
possible influence of the temperature treatment on the catalytic performance $[22,42]$. In order to gain insight into structure-performance correlations, the crystal structure and morphology of the prepared $\mathrm{MoO}_{3}$, as well as their acidity, specific surface areas and nitrogen contents were thoroughly analyzed. All materials were tested in the oxidation of propylene to acrolein and, finally, characterized after the catalytic tests to evaluate possible changes of the applied materials during time on stream.

\section{Experimental}

\subsection{Materials preparation}

For the hydrothermal synthesis of pure molybdenum trioxide $\left(\mathrm{MoO}_{3}\right)$ different precursors and acids were used (cf. Table 1 and Table 2). The samples are named based on the precursor, the acid $\left(\mathrm{HNO}_{3}\right.$ and $\mathrm{HOAc}$ for acetic acid), $\mathrm{pH}$ value (adjusted by $\mathrm{HNO}_{3}$ ), additional calcination (at $550{ }^{\circ} \mathrm{C}$ ) and special methods e.g. FSP for flame spray pyrolysis (detailed denotation see further below). All chemicals were analytical grade and used without further purification. The preparation was performed as follows. Ammonium heptamolybdate tetrahydrate $\left(\mathrm{AHM} ;\left(\mathrm{NH}_{4}\right)_{6} \mathrm{Mo}_{7} \mathrm{O}_{24} \cdot 4 \mathrm{H}_{2} \mathrm{O}\right)$ was dissolved in $100 \mathrm{ml}$ deionized water under continuous stirring at room temperature. The $\mathrm{pH}$ value was adjusted to $0-2$ by using 2.2 $\mathrm{M} \mathrm{HNO}_{3}$, the resulting colorless solution was stirred for 30 minutes and subsequently heated in sealed $250 \mathrm{ml}$ autoclaves (Berghof) with Teflon inlays at $180{ }^{\circ} \mathrm{C}$ for $24 \mathrm{~h}$ in an oven.

Table 1: Characterization of the as-prepared, calcined and used samples by BET, $\mathrm{NH}_{3}-\mathrm{TPD}, \mathrm{H}_{2}-\mathrm{TPR}$ and quantitative nitrogen analysis.

\begin{tabular}{|c|c|c|c|c|c|c|c|c|c|}
\hline \multirow[t]{2}{*}{ Sample } & \multicolumn{3}{|c|}{$\begin{array}{c}\text { Specific surface } \\
\text { area }(\text { BET }) \\
{\left[\mathbf{m}^{2} / \mathbf{g}\right]} \\
\end{array}$} & \multicolumn{3}{|c|}{$\begin{array}{c}\mathrm{NH}_{3}-\mathrm{TPD} \\
{\left[\mu \mathrm{mol} \mathrm{NH}_{3} / \mathrm{g}_{\mathrm{cat}}\right]}\end{array}$} & \multicolumn{2}{|c|}{ 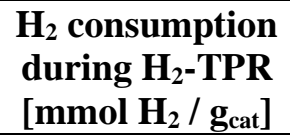 } & \multirow{2}{*}{$\begin{array}{c}\begin{array}{c}\text { Amount of } \mathbf{N} \\
\text { [wt.\%] }\end{array} \\
\text { calc. }\end{array}$} \\
\hline & $\begin{array}{l}\text { as- } \\
\text { prep. }\end{array}$ & calc. & used & $\begin{array}{c}\text { as- } \\
\text { prep. }\end{array}$ & calc. & $\begin{array}{l}\text { us } \\
\text { ed }\end{array}$ & as-prep. & calc. & \\
\hline AHM_decomposed & - & $<1$ & & - & 2.8 & & & & $0.024 \pm 0.003$ \\
\hline FSP_MoO3 & 43 & 16 & & 45.6 & 1.6 & & & & n.d. \\
\hline $\mathrm{MoO} 3 \cdot 2 \mathrm{H} 2 \mathrm{O} \_\mathrm{HOAc}$ & 11 & 9 & 2 & & 8.4 & 1.4 & 13 & 16 & $<0.01$ \\
\hline $\mathrm{MoO} 3 \cdot 2 \mathrm{H} 2 \mathrm{O} \_\mathrm{HNO} 3$ & 7 & 4 & & 11.7 & 12.0 & 2.1 & 16 & 18 & $<0.01$ \\
\hline AHM_pH2_24h & $<1$ & $<1$ & & & 4.7 & 1.4 & & & n.d \\
\hline AHM_pH1_24h & $<1$ & $<1$ & & & 3.0 & & 16 & 17 & $0.011 \pm 0.001$ \\
\hline AHM_pH0_24h & & 10 & 4 & & 10.2 & 8.1 & & 16 & $<0.01$ \\
\hline
\end{tabular}

Alternatively $\mathrm{MoO}_{3} \cdot 2 \mathrm{H}_{2} \mathrm{O}$ (synthesized according to a literature procedure [43]) was used as molybdenum precursor and diluted nitric acid (2.2 M) or acetic acid (25 vol.\%) were added to the 
Teflon liners as reported in literature [12]. The resulting suspensions were heated in sealed $250 \mathrm{ml}$ autoclaves (Berghof) at $180{ }^{\circ} \mathrm{C}$ for $48 \mathrm{~h}$ in an oven.

Table 2: Morphology, particle size and calculated ratios of the intensities of the reflections in the X-ray diffraction pattern in Figure 3a.

\begin{tabular}{|c|c|c|c|c|c|c|}
\hline \multirow[t]{2}{*}{ Sample } & \multirow[t]{2}{*}{ Morphology } & \multicolumn{2}{|c|}{ Particle size } & \multirow{2}{*}{$\begin{array}{c}\mathbf{I}_{(\mathbf{0 2 0})} / \sum_{\%} \mathbf{I}_{(\mathbf{h k l})}{ }^{\mathbf{a}} \\
\%\end{array}$} & \multirow{2}{*}{$\begin{array}{c}\mathbf{I}_{(\mathbf{0 4 0})} / \sum_{\%} \mathbf{I}_{(\mathbf{h k l})^{\mathbf{a}}} \\
\%\end{array}$} & \multirow{2}{*}{$\begin{array}{c}\mathbf{I}_{(021)} / \sum \mathbf{I}_{(\mathbf{h k l})}{ }^{\mathrm{a}} \\
\%\end{array}$} \\
\hline & & width & length & & & \\
\hline AHM_decomposed & stacked plates & $1-2$ & $1-2 \mu \mathrm{m}$ & 17 & 10 & 31 \\
\hline AHM_decomposed_used & stacked plates & $\begin{array}{l}\mu \mathrm{m} \\
1-2 \\
\mu \mathrm{m}\end{array}$ & $1-2 \mu \mathrm{m}$ & 13 & 13 & 40 \\
\hline FSP_MoO3 & $\begin{array}{l}\text { rods and } \\
\text { plates }\end{array}$ & $\begin{array}{c}10-25 \\
\mathrm{~nm}\end{array}$ & $\begin{array}{l}25-50 \\
\mathrm{~nm}\end{array}$ & 18 & 36 & 12 \\
\hline FSP_MoO3_used & n.d. & & & 8 & 26 & 6 \\
\hline FSP_MoO3_HNO3_calc & n.d. & & & 14 & 40 & 7 \\
\hline FSP_MoO3_HNO3_calc_used & n.d. & & & 7 & 32 & 14 \\
\hline $\begin{array}{c}\mathrm{MoO} 3 \cdot 2 \mathrm{H} 2 \mathrm{O} \_\mathrm{HOAc} \text { treated in } \\
\mathrm{NH} 3 \_ \text {calc }\end{array}$ & n.d. & & & 9 & 27 & 22 \\
\hline$\underset{\mathrm{NH} 3 \text { _used }}{\mathrm{MoO} 3 \cdot 2 \mathrm{H} 2 \mathrm{O} \text { HOAc_treated in }}$ & n.d. & & & 21 & 38 & 7 \\
\hline $\mathrm{MoO} 3 \cdot 2 \mathrm{H} 2 \mathrm{O} \_\mathrm{HOAc}$ _calc & rods & $\begin{array}{c}200 \\
\mathrm{~nm}\end{array}$ & $\begin{array}{l}\text { up to } 1 \\
\mu \mathrm{m}\end{array}$ & 33 & 33 & 16 \\
\hline MoO3·2H2O_HOAc_calc_used & plates & $2-5$ & $4-8 \mu \mathrm{m}$ & 32 & 32 & 15 \\
\hline $\mathrm{MoO} 3 \cdot 2 \mathrm{H} 2 \mathrm{O} \_\mathrm{HNO} 3 \_$calc & rods & $\begin{array}{l}\mu \mathrm{m} \\
600 \\
\mathrm{~nm}\end{array}$ & $\begin{array}{l}10-20 \\
\mu \mathrm{m}\end{array}$ & 43 & 34 & 8 \\
\hline $\mathrm{MoO} 3 \cdot 2 \mathrm{H} 2 \mathrm{O} \_\mathrm{HNO} 3$ _calc_used & $\begin{array}{l}\text { rods and } \\
\text { plates }\end{array}$ & $\begin{array}{c}600- \\
800 \\
\mathrm{~nm}\end{array}$ & $10 \mu \mathrm{m}$ & 45 & 36 & 3 \\
\hline AHM_pH2_24h_calc & irregular & $2 \mu \mathrm{m}$ & $7 \mu \mathrm{m}$ & 14 & 15 & 41 \\
\hline AHM_pH2_24h_calc_used & stacked plates & $1 \mu \mathrm{m}$ & $2 \mu \mathrm{m}$ & 20 & 20 & 30 \\
\hline AHM_pH1_24h_calc & $\begin{array}{l}\text { hexagonal } \\
\text { prismatic } \\
\text { rods }\end{array}$ & $\begin{array}{l}\mathrm{d}=9- \\
11 \mu \mathrm{m}\end{array}$ & $\begin{array}{c}50-60 \\
\mu \mathrm{m}\end{array}$ & 18 & 17 & 36 \\
\hline AHM_pH1_24h_calc_used & stacked plates & $2-3$ & $\sim 3 \mu \mathrm{m}$ & 29 & 16 & 34 \\
\hline AHM_pH0_24h_calc & rods & $\begin{array}{l}\mu \mathrm{m} \\
200\end{array}$ & $1-2 \mu \mathrm{m}$ & 37 & 34 & 12 \\
\hline AHM_pH0_24h_calc_used & rods & $\begin{array}{l}300 \\
\mathrm{~nm}\end{array}$ & $2-3 \mu \mathrm{m}$ & 32 & 31 & 17 \\
\hline
\end{tabular}

a: $\sum I_{(h k))}$ was calculated for the reflections between 10 and $50^{\circ} ; \sum I_{(h k l)}=I_{(020)}+I_{(110)}+I_{(040)}+I_{(021)}+I_{(111)}+$ $I_{(060)}+I_{(021)}$

After the autoclaves were cooled down to room temperature, the solid product was separated by filtration, washed with water, ethanol and finally acetone. The resulting powder was dried at room temperature and ambient pressure. Afterwards the samples were calcined at $550{ }^{\circ} \mathrm{C}$ for $4 \mathrm{~h}$. These samples are denoted here as followed: precursor_pH_synthesis time or precursor_acid.

In addition, $\mathrm{MoO}_{3}$ was prepared by one-step flame spray pyrolysis (FSP) with a set-up similar to the one reported in ref. [44] which is based on previous designs by Mädler and Pratsinis [45-48]. The 
precursor solution was prepared by dissolving $9.6 \mathrm{~g} \mathrm{Mo(VI)-2-ethylhexanoate} \mathrm{in} 100 \mathrm{ml}$ xylene. The precursor solution was filled in a syringe and pumped at $5 \mathrm{ml} / \mathrm{min}$. Oxygen was used as dispersion gas; the supporting flame was a mixture of oxygen and methane. The sample was collected on a cooled filter (Whatman) and calcined at $550{ }^{\circ} \mathrm{C}$ for $4 \mathrm{~h}$ (FSP_MoO3).

$1 \mathrm{~g}$ of the uncalcined flame made $\mathrm{MoO}_{3}$ was also treated hydrothermally in $2.2 \mathrm{M} \mathrm{HNO}_{3}$ for $24 \mathrm{~h}$ at $180{ }^{\circ} \mathrm{C}$ (FSP_MoO3_HNO3). For comparison with the hydrothermally synthesized and flame made samples ammonium heptamolybdate was thermally decomposed for $10 \mathrm{~h}$ at $550{ }^{\circ} \mathrm{C}$ to prepare pure $\alpha$ $\mathrm{MoO}_{3}\left(\mathrm{AHM} \_\right.$decomposed).

To analyze the influence of nitrogen incorporation into $\alpha-\mathrm{MoO}_{3}$ on the catalytic performance of the hydrothermally synthesized materials, the sample prepared from $\mathrm{MoO}_{3} \cdot 2 \mathrm{H}_{2} \mathrm{O}$ and acetic acid was also treated in ammonia. The sample was dried in synthetic air at $110{ }^{\circ} \mathrm{C}$ for $2 \mathrm{~h}$ and then treated in $5 \%$ $\mathrm{NH}_{3}$ in $\mathrm{N}_{2}$ for $10 \mathrm{~h}$ using a flow of $500 \mathrm{ml} / \mathrm{min}$ at $250{ }^{\circ} \mathrm{C}$. This resembles the procedure described by Kühn et al. [49]. Afterwards the resulting material was calcined at $550{ }^{\circ} \mathrm{C}$ for $4 \mathrm{~h}$ like all the other samples.

\subsection{Characterization}

The structure and morphology of the samples were determined by powder X-ray diffraction (PXRD) using a Bruker D8 Advance in the range $2 \theta=8-80^{\circ}$ (step size $0.016^{\circ}$ ) with $\mathrm{Cu} \mathrm{K} \alpha$ radiation (Nifilter, $45 \mathrm{~mA}, 35 \mathrm{kV}$ ) in Bragg-Brentano geometry on rotating sample holders. Raman spectra were recorded with a Horiba Jobin Yvon spectrometer (LabRam) attached to an Olympus microscope (BX 40) using a HeNe laser with $632.8 \mathrm{~nm}$ excitation. Spectra were measured in the $100-1100 \mathrm{~cm}^{-1}$ range with the sample on an object slide without pretreatment.

Specific surface areas (SSA) were determined by nitrogen adsorption at its boiling point (Belsorp II mini, BEL Japan Inc.) using multipoint BET theory in the $\mathrm{p} / \mathrm{p}_{0}=0.05-0.3$ range. For scanning electron microscopy (SEM), performed on a Quanta 200 ESEM (FEG) microscope at the Centre of Electron Nanoscopy (CEN) at DTU, samples were deposited on a carbon foil on aluminum stubs and coated with carbon to improve the conductivity. 
Bright field transmission electron microscopy (Tecnai T20, DTU-CEN) was measured on the asprepared powders supported on lacey carbon copper grids. The oxidic catalyst powder was transferred to the grid by dipping it several times in the powder and removing loosely bound excess.

Temperature programmed reduction $\left(\mathrm{H}_{2}\right.$-TPR) was conducted in a tubular reactor using $100 \mathrm{mg}$ of sample and a flow of $96 \mathrm{ml} / \mathrm{min}$ with a gas composition of $5 \% \mathrm{H}_{2}$ in argon. The reactor was heated with $5 \mathrm{~K} / \mathrm{min}$ from room temperature to $1000{ }^{\circ} \mathrm{C}$. Reduction led to a decrease in hydrogen concentration which was detected by a thermal conductivity detector. Condensation of the produced water in the tubes was avoided by using a cold trap, which was cooled with liquid nitrogen.

The amount of acidic sites on the surface was estimated using temperature programmed desorption of ammonia ( $\mathrm{NH}_{3}$-TPD) by heating up to $600{ }^{\circ} \mathrm{C}$ with $10 \mathrm{~K} / \mathrm{min}$ and on-line gas analysis by FTIR (MultiGas ${ }^{\mathrm{TM}}$ Analyzer, MKS instruments). For this purpose $400 \mathrm{mg}$ of catalyst were fixed with glass wool in a tubular glass reactor. The reactor was heated up with a rate of $10 \mathrm{~K} / \mathrm{min}$ and the catalyst was pretreated for $1 \mathrm{~h}$ at $500{ }^{\circ} \mathrm{C}$ in synthetic air $(500 \mathrm{ml} / \mathrm{min})$. After cooling down to room temperature, the gas was changed to pure nitrogen and the tubes were flushed to remove oxygen. After saturation with ammonia at $50-60{ }^{\circ} \mathrm{C}$ using $500 \mathrm{ml} / \mathrm{min}$ with a composition of $1000 \mathrm{ppm} \mathrm{NH}_{3}$ in $\mathrm{N}_{2}$, the excess amount of $\mathrm{NH}_{3}$ was removed (flushing with $\mathrm{N}_{2}$ until steady minimum of $\mathrm{NH}_{3}$ in the exit gas). Quantitative nitrogen analysis was carried out using hot gas extraction method (LECO TC 600). The samples were heated in a graphite crucible under flowing helium and thermally decomposed. The amount of $\mathrm{N}_{2}$ gas was determined by a thermal conductivity detector. Each measurement was repeated twice and a standard deviation was calculated.

X-ray absorption spectroscopy (XAS) was performed at the SNBL beamline (BM01B) at the ESRF synchrotron radiation source (Grenoble, France). The samples were diluted with cellulose and pressed as a pellet for ex situ measurements in transmission mode at the Mo K edge (20.0 keV). XAS data were processed using the IFFEFIT software package [50].

\subsection{Catalytic tests}

Propylene conversion and acrolein / $\mathrm{CO}_{x}$ selectivity were measured in a continuous flow fixed bed reactor, using a $\mathrm{U}$-shaped quartz reactor with $4 \mathrm{~mm}$ inner diameter. The catalyst powders were crushed and sieved to $150-300 \mu \mathrm{m}$ sized particles and $500 \mathrm{mg}$ of sample were loaded in the reactor without 
dilution and stabilized with quartz wool. The quartz reactor was connected to a commercial test unit (ChimneyLab Europe) with calibrated mass flow controllers (Brooks) and placed in an oven (Watlow) [51]. A thermocouple was placed inside the reactor just touching the catalyst bed to measure the reaction temperature and a pressure transducer placed upstream of the reactor monitored the actual reaction pressure. The catalysts were pre-oxidized in dry air at $550{ }^{\circ} \mathrm{C}$ in the reactor. Activity tests were performed using a gas composition of $\mathrm{C}_{3} \mathrm{H}_{6} / \mathrm{O}_{2} / \mathrm{N}_{2}=5 / 25 / 70$ and flows of 50, 80, 120, 180, 260 $\mathrm{Nml} / \mathrm{min}$. Gas analysis was performed using a dual channel GC-MS (Thermo Fischer) with a TCD detector (quantification of $\mathrm{N}_{2}, \mathrm{O}_{2}, \mathrm{CO}$ and $\mathrm{CO}_{2}$ ) and a FID detector parallel with the MS (identification and quantification of light hydrocarbons and oxygenated products). The measured concentrations were corrected for expansion of the gas due to combustion using the nitrogen signal as internal standard, before calculating the conversion of propylene and the selectivity to acrolein.

\section{Results and Discussion}

\subsection{Structural characterization and composition}

Ammonium heptamolybdate was treated with varying amount of nitric acid under hydrothermal conditions at $180{ }^{\circ} \mathrm{C}$ for $24 \mathrm{~h}$. The product phases and morphologies were strongly dependent on the $\mathrm{pH}$ value and the following calcination step. Figure 1 compares the SEM and XRD data for hydrothermal synthesis at $\mathrm{pH}=0,1$ and 2 directly after hydrothermal synthesis and after calcination at $550{ }^{\circ} \mathrm{C}$. At $\mathrm{pH}=2$ a phase corresponding to hexagonal $\left(\mathrm{NH}_{4}\right)_{0.944} \mathrm{H}_{3.304} \mathrm{Mo}_{5.292} \mathrm{O}_{18}$ [52] (JCPDS no. 831175), showing a hexagonal prismatic morphology, was formed. Decreasing the $\mathrm{pH}$ value to 1 resulted mainly in $\left(\mathrm{NH}_{4}\right)_{0.944} \mathrm{H}_{3.304} \mathrm{Mo}_{5.292} \mathrm{O}_{18}$ but also traces of $\alpha-\mathrm{MoO}_{3}$ were found in the diffraction pattern as indicated by the reflections at $23.3,27.3$ and $39.0^{\circ}$. The particles were also prismatic and hexagonal but more agglomerated and additionally some needles were present, according to SEM (Figure 1). Synthesis at $\mathrm{pH}=0$ led to the formation of pure $\alpha-\mathrm{MoO}_{3}$ [53] (JCPDS no. 5-0508) with rod-like morphology. After calcination at $550{ }^{\circ} \mathrm{C}$ for $4 \mathrm{~h}$ the diffraction pattern of all three samples showed solely $\alpha-\mathrm{MoO}_{3}$ but the relative intensities of the reflections characteristic for orthorhombic $\alpha-\mathrm{MoO}_{3}$ were different, indicating different morphologies. This was confirmed by the SEM images shown in Figure 1. The hexagonal prismatic particles obtained from ammonium heptamolybdate and $\mathrm{HNO}_{3}$ at $\mathrm{pH}=2$ were transformed into randomly shaped particles, showing that the morphology could not be 
conserved after calcination. The sample prepared at $\mathrm{pH}=1$ still showed a hexagonal prismatic morphology and the sample prepared at $\mathrm{pH}=0$ maintained its rod-like morphology after calcination. The different phases of the hydrothermally synthesized products can be rationalized by the polymolybdate species present in the solution depending on its $\mathrm{pH}$ value. In a mildly acidic solution $\left[\mathrm{Mo}_{7} \mathrm{O}_{24}\right]^{6-}$ and $\left[\mathrm{Mo}_{8} \mathrm{O}_{26}\right]^{4-}$ are the most abundant species, while at very low $\mathrm{pH}(<1)\left[\mathrm{Mo}_{36} \mathrm{O}_{112}\right]^{8-}$, $\left[\mathrm{HMoO}_{3}\right]^{+},\left[\mathrm{H}_{2} \mathrm{Mo}_{2} \mathrm{O}_{6}\right]^{2+}$ and $\left[\mathrm{H}_{3} \mathrm{Mo}_{2} \mathrm{O}_{6}\right]^{3+}$ are formed. Further decrease of the $\mathrm{pH}$ value leads to $\mathrm{MoO}_{3}$ - $2 \mathrm{H}_{2} \mathrm{O}$ [54]. The heptapolymolybdate anions $\left[\mathrm{Mo}_{7} \mathrm{O}_{24}\right]^{6-}$ are transformed to neutral $\mathrm{Mo}_{7} \mathrm{O}_{21}\left(\alpha-\mathrm{MoO}_{3}\right)$. First $\mathrm{MoO}_{3} \cdot 2 \mathrm{H}_{2} \mathrm{O}$ is formed, which will lose water in two steps with increasing temperature [54].

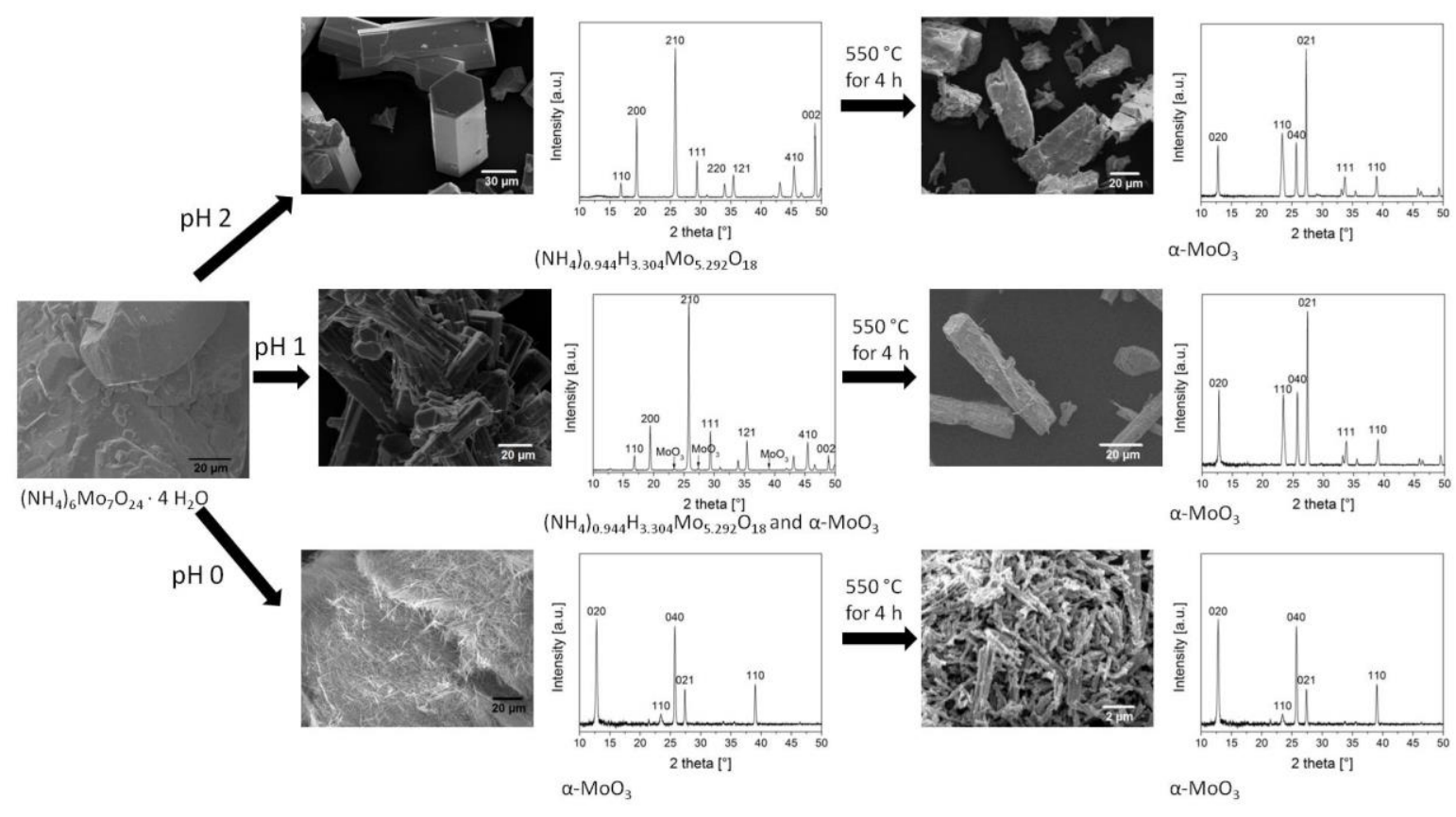

Figure 1: Preparation of different samples from ammonium heptamolybdate (SEM image on the left) and nitric acid by variation of the $\mathrm{pH}$ value (directly after synthesis: SEM images and XRD pattern in the middle, after calcinations at $550^{\circ}$ SEM and XRD pattern on the right). Note that $\left(\mathrm{NH}_{4}\right)_{0.944} \mathrm{H}_{3.304} \mathrm{Mo5}_{2.292} \mathrm{O}_{18}$ is one of the possible ammonia-containing Mophases that may be formed.

In an alternative preparation route, $\mathrm{MoO}_{3} \cdot 2 \mathrm{H}_{2} \mathrm{O}$ was prepared according to a literature procedure [43] and then hydrothermally treated with nitric and acetic acid, respectively at $180{ }^{\circ} \mathrm{C}$ for $48 \mathrm{~h}$. The X-ray diffraction pattern of the two obtained products showed the characteristic reflections of $\alpha-\mathrm{MoO}_{3}$ (see electronic supporting information [ESI]). Both samples also exhibited a rod-like morphology, as can be seen in Figure 2a and c. Using nitric acid led to longer and thicker rods than preparation with acetic acid and consequently MoO3·2H2O_HNO3 had a smaller surface area than MoO3·2H2O_HOAc (7 $\mathrm{m}^{2} / \mathrm{g}$ and $11 \mathrm{~m}^{2} / \mathrm{g}$ respectively, cf. Table 1). This is in agreement with literature [12], reporting that weak organic acids lead to particles of nanoscale diameter, whereas strong inorganic acids support the 
formation of rods in the microscale. The rod-like morphology (Figure $2 b$ and d) and $\alpha-\mathrm{MoO}_{3}$ phase could again be retained after calcination.
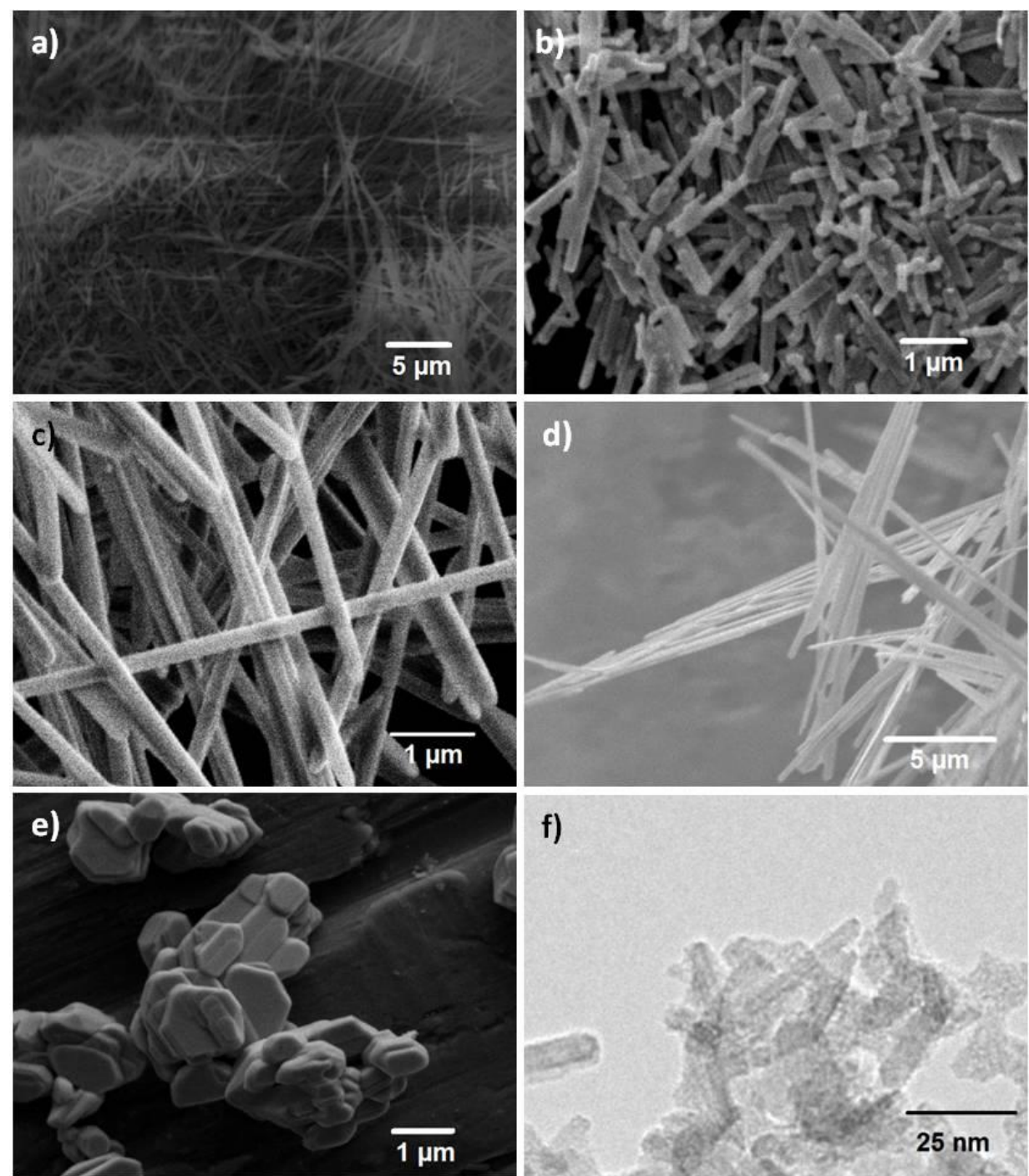

Figure 2: $\mathrm{SEM}$ images of a) $\mathrm{MoO} 3 \cdot 2 \mathrm{H} 2 \mathrm{O} \mathrm{HOAc}$, b) $\mathrm{MoO} 3 \cdot 2 \mathrm{H} 2 \mathrm{O}$ HOAc calc, c) $\mathrm{MoO} 3 \cdot 2 \mathrm{H} 2 \mathrm{O} \mathrm{HNO} 3$, d) MoO3.2H2O_HNO3_calc and e) AHM_decomposed. TEM images of the flame made sample FSP_MoO3 (f)

Ammonium heptamolybdate was completely decomposed to $\alpha-\mathrm{MoO}_{3}$ after treatment at $550{ }^{\circ} \mathrm{C}$ for 10 $\mathrm{h}$ according to the diffraction pattern and Raman spectrum shown in Figure 3, but quantitative nitrogen analysis indicated a relatively high nitrogen content in this sample (Table 1). Only $\alpha-\mathrm{MoO}_{3}$ prepared by hydrothermal synthesis from $\mathrm{MoO}_{3} \cdot 2 \mathrm{H}_{2} \mathrm{O}$ and acetic acid treated in ammonia $\left(\mathrm{MoO}_{3} \cdot 2 \mathrm{H}_{2} \mathrm{O} \_\mathrm{HOAc} \_\right.$treated in $\mathrm{NH}_{3} \_$calc) contained more nitrogen than AHM_decomposed.

All calcined samples consisted of pure $\alpha-\mathrm{MoO}_{3}$ and no contributions of other crystalline phases such as $\beta-\mathrm{MoO}_{3}$ or impurities could be detected in the diffraction pattern or the Raman spectra (Figure 3). All the Raman spectra (Figure 3b) showed the characteristic bands at 992, 817, 288, 280, 154, 126 and 
$112 \mathrm{~cm}^{-1}$ (assignment, cf. [55]). Comparing the X-ray diffraction pattern of the prepared samples with the reference pattern (JCPDS no. 5-0508) evidenced that the relative intensities of the different reflections varied for the different samples. Each reflection can be assigned to an exposed lattice plane. In the reference pattern (JCPDS no. 5-0508) the reflection at $27.3^{\circ}(021)$ had the highest intensity and also the reflection at $23.3^{\circ}(110)$ was relatively intense. This is in line with the samples prepared from AHM by thermal decomposition or by hydrothermal synthesis at $\mathrm{pH}=1$ and $\mathrm{pH}=2$.
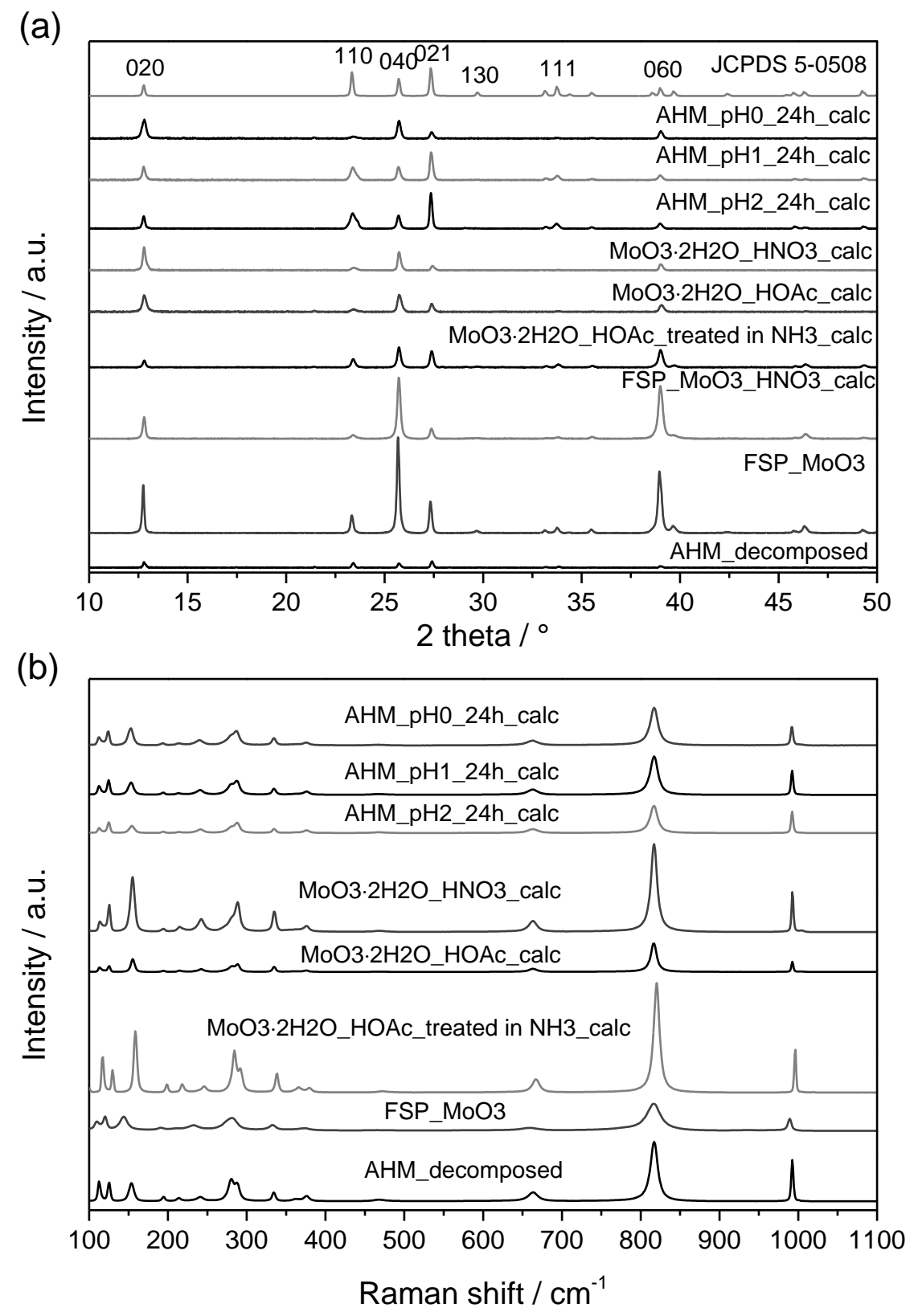

Figure 3: X-ray diffraction patterns (a) and Raman spectra (b) of the differently prepared samples after calcination at $550{ }^{\circ} \mathrm{C}$. All samples showed pure $\alpha-\mathrm{MoO}_{3}$ but with distinct intensity variation of the reflections. 
All other samples showed a rod-like morphology in the SEM images and consequently in the diffraction pattern the $(0 \mathrm{k} 0)$ reflections $\left(12.7,25.7\right.$ and $\left.38.9^{\circ}\right)$ were more intense than the other reflections. In Table 2 the particle morphology of the calcined samples are summarized as well as the relative intensities for different reflections $\left((020)\right.$ at $12.7^{\circ},(040)$ at $25.7^{\circ}$ and $(021)$ at $\left.27.3^{\circ}\right)$. The intensity of the corresponding reflections was divided by the sum of the intensities of all reflections between 10 and $50^{\circ}$. High values for $\mathrm{I}_{(020)} / \sum \mathrm{I}_{(\mathrm{hkl})}$ and $\mathrm{I}_{(040)} / \sum \mathrm{I}_{(\mathrm{hkl})}$ imply the preferred exposure of the (0k0) facets and the presence of $\alpha-\mathrm{MoO}_{3}$ in the form of rods/fibers or plates. All other samples, which had an irregular, stacked plate-like or hexagonal prismatic morphology, reached additionally high values for $\mathrm{I}_{(021)} / \sum \mathrm{I}_{(\mathrm{hkl})}$, whereas only in the diffraction pattern of the thermally decomposed AHM the reflection at $27.3^{\circ}(021)$ showed the highest intensity, which agrees well with the reference pattern. Comparison of the different X-ray diffraction pattern already gives an insight into the product morphology of the corresponding $\alpha-\mathrm{MoO}_{3}$. Higher intensities of (0k0) planes compared to other (hkl) planes are an indication for the anisotropic growth of $\mathrm{MoO}_{3}$ as well as the preferred orientation of the rods [54]. This is supported by the Raman spectra. According to Dieterle et al. [55] the bands at 992 $\mathrm{cm}^{-1}$ and $817 \mathrm{~cm}^{-1}$ can both be assigned to terminal $\mathrm{Mo}=\mathrm{O}$ stretching vibrations, corresponding to the asymmetric stretching vibrations along the $a$-axis and the longer $\mathrm{Mo}=\mathrm{O}$ bond vibrations along the $b$ axis. The Raman intensities were normalized to the band with the highest intensity at $817 \mathrm{~cm}^{-1}$ and the normalized spectra are depicted in Figure 4 in the energy range $790-840$ and $980-1000 \mathrm{~cm}^{-1}$. A lower normalized intensity for the band at $992 \mathrm{~cm}^{-1}$ (lower I(992)/I(817) intensity ratio) indicates a lower amount of (010) facets which is typical for $\mathrm{MoO}_{3}$ rods.

In addition to X-ray diffraction and Raman spectroscopy the three samples, which showed the rod-like morphology (AHM_pH0_24h_calc, MoO3·2H2O_HNO3_calc, MoO3.2H2O_HOAc_calc), were analyzed by X-ray absorption spectroscopy (XAS). Strong backscattering of the Mo second shell neighbors in the Fourier-transformed extended X-ray absorption fine structure (EXAFS) spectra confirmed that exclusively $\alpha-\mathrm{MoO}_{3}$ was prepared which has an almost linear Mo-O-Mo geometry ("focusing effect" for backscattering, see ESI and [56]). 


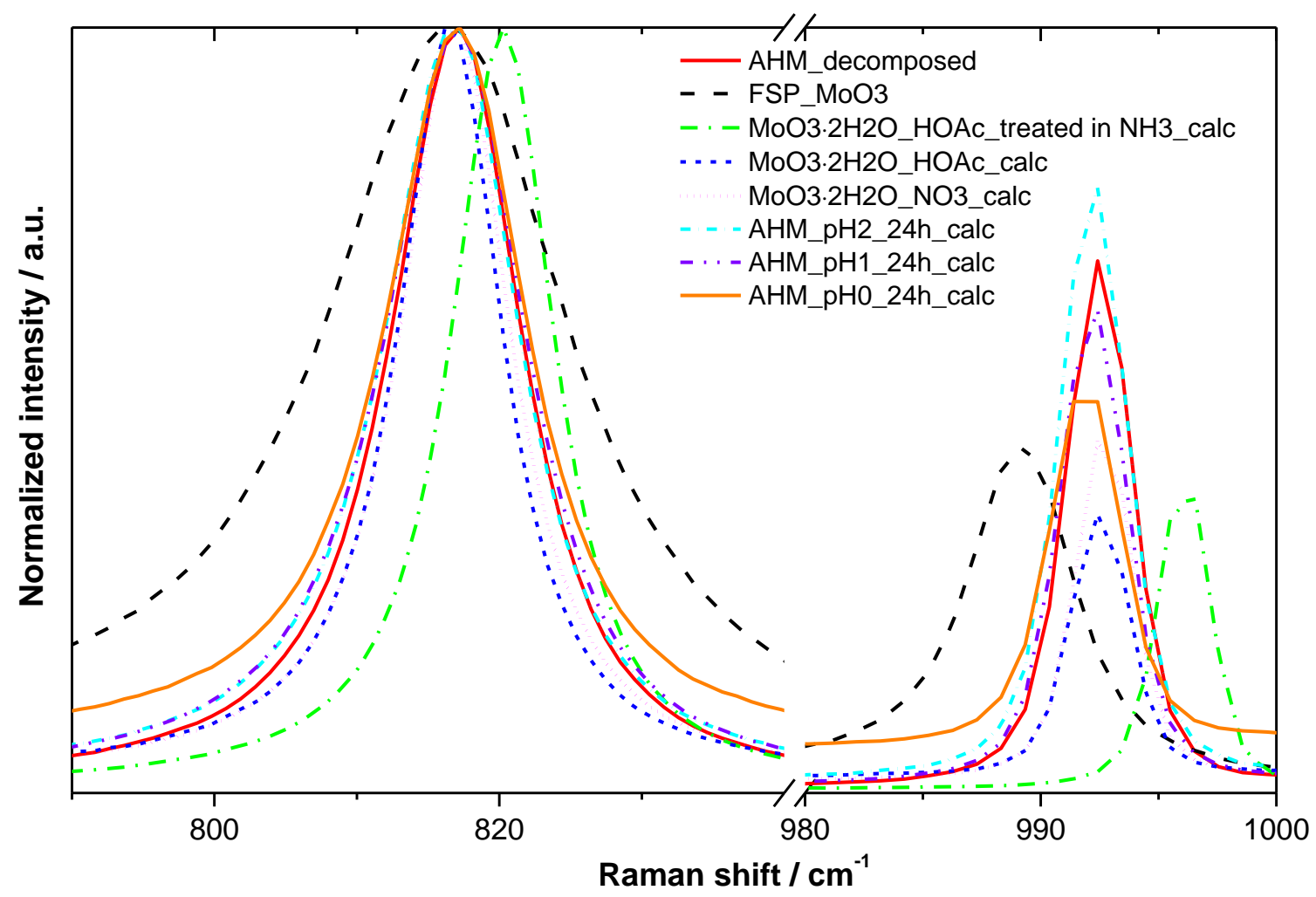

Figure 4: Raman spectra of the calcined samples in the energy range $790-840 \mathrm{~cm}^{-1}$ and $980-1000 \mathrm{~cm}^{-1}$. The spectra are normalized to the highest intensity band at $817 \mathrm{~cm}^{-1}$ and the relative intensity of the band at $992 \mathrm{~cm}^{-1}$ of the various samples is given in the table.

\subsection{Reducibility and acidity of $\alpha-\mathrm{MoO}_{3}$ samples}

Since both redox-activity of $\alpha-\mathrm{MoO}_{3}$ and its acidity play an important role for the catalytic performance [57], temperature programmed reduction (TPR) and ammonia adsorption were used for further characterization. In Figure 5 the TPR results are displayed plotting the $\mathrm{H}_{2}$ consumption as a function of the temperature. The spectra can be divided in two regions: a low temperature region showing the reduction of $\mathrm{MoO}_{3}$ to first a sub-oxide like $\mathrm{Mo}_{4} \mathrm{O}_{11}$ indicated by the shoulder at $550-640$ ${ }^{\circ} \mathrm{C}$ (cf. also studies by Ressler et al. [60]) then to $\mathrm{MoO}_{2}$ and a high temperature region, where $\mathrm{MoO}_{2}$ is further reduced to Mo metal. At $1000{ }^{\circ} \mathrm{C}$ all samples were completely reduced to metallic Mo, which was proven by X-ray diffraction measurements (cf. Figure S3 XRD pattern in ESI). The samples synthesized from $\mathrm{MoO}_{3} \cdot 2 \mathrm{H}_{2} \mathrm{O}$ could be reduced at lower temperature than the samples prepared from ammonium heptamolybdate. Calcination of the sample prepared from $\mathrm{MoO}_{3} \cdot 2 \mathrm{H}_{2} \mathrm{O}$ and $\mathrm{HNO}_{3}$ led to a shift in reduction temperature by $30 \mathrm{~K}$ to higher temperature $\left(704{ }^{\circ} \mathrm{C}\right)$ compared to the as-prepared sample $\left(674{ }^{\circ} \mathrm{C}\right)$. The amount of hydrogen consumed per catalyst mass $\left(\mathrm{n}\left(\mathrm{H}_{2}\right) / \mathrm{m}(\mathrm{cat})\right)($ Table 1$)$ was 
the same for all measured samples $\left(13-18 \mathrm{mmol} \mathrm{H}_{2} / \mathrm{g}_{\text {catalyst }}\right)$, showing that the as-prepared samples were completely oxidized.

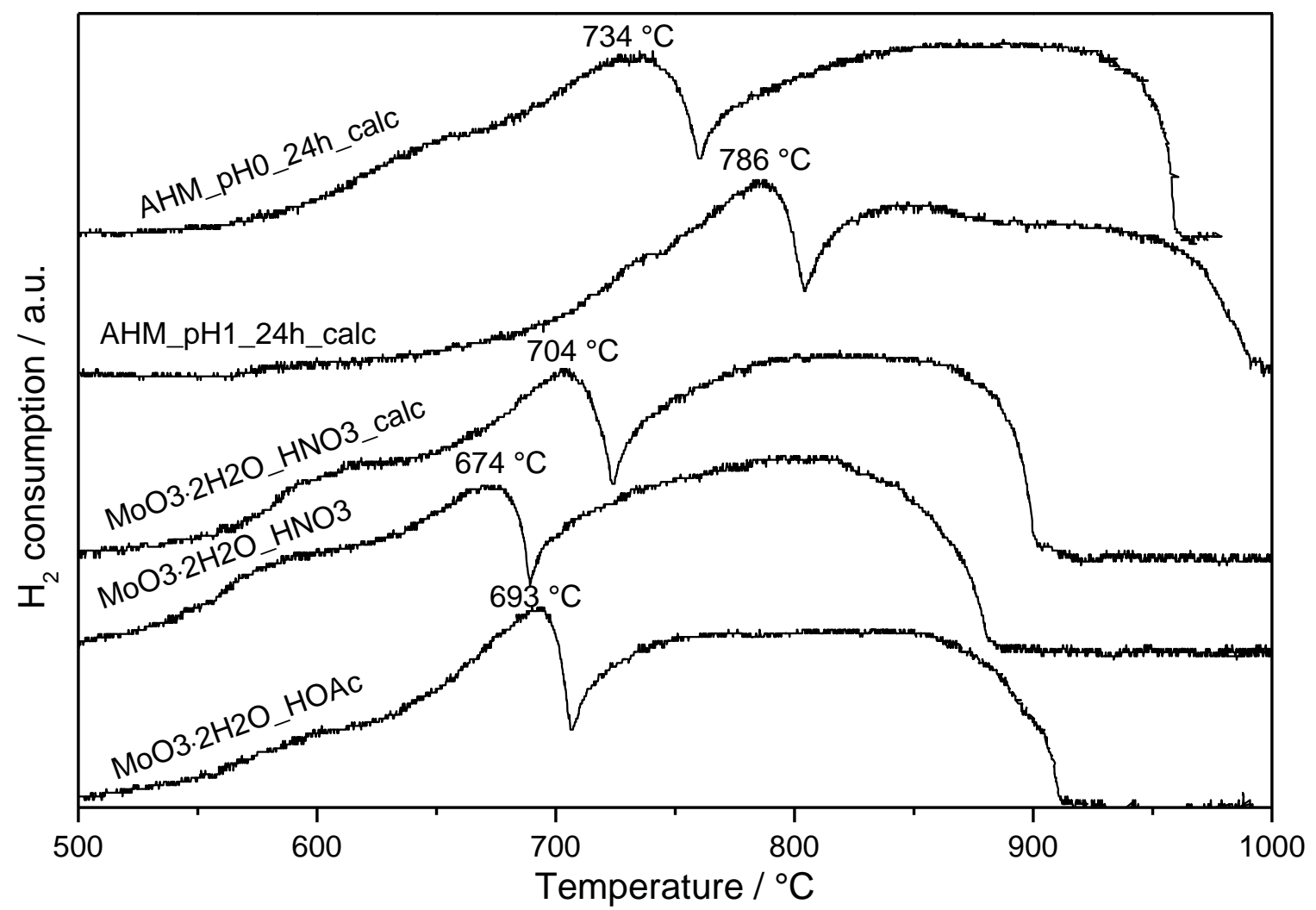

Figure 5: $\mathrm{H}_{2}$-TPR of differently prepared $\alpha-\mathrm{MoO}_{3}\left(100 \mathrm{mg}\right.$ catalyst, $5 \mathrm{~K} / \mathrm{min}$ from room temperature to $1000{ }^{\circ} \mathrm{C}$, flow of 96 $\mathrm{ml} / \mathrm{min}, 5 \% \mathrm{H}_{2}$ in argon). Samples synthesized from $\mathrm{MoO}_{3} \cdot 2 \mathrm{H}_{2} \mathrm{O}$ are reduced to $\mathrm{MoO}_{2}$ at lower temperature than samples prepared from AHM.

$\mathrm{NH}_{3}$-TPD was performed for different as-prepared and calcined samples and the desorbed $\mathrm{NH}_{3}$ concentration was plotted as a function of the temperature in Figure 6. All samples showed relatively low acidity. The calculated amounts of desorbed ammonia per gram of catalyst (Table 1) were lower than the values for supported $\mathrm{MoO}_{3}$-catalysts or potassium doped unsupported $\mathrm{MoO}_{3}$ studied by Bian et al. [58]. The only exception was the flame made sample, which showed a large amount of ammonia adsorption sites; however, the acidity strongly decreased after calcination at $550{ }^{\circ} \mathrm{C}$. One of the reasons for the decrease in acidity is probably the decrease in surface area (from $43 \mathrm{~m}^{2} / \mathrm{g}$ to $16 \mathrm{~m}^{2} / \mathrm{g}$ ), although the amount of ammonia adsorption sites decreased stronger than the surface area (cf. Table 1). Calcination of MoO3.2H2O_HNO3 did not reduce the amount of $\mathrm{NH}_{3}$ adsorption sites on the catalyst surface (Table 1), but the as-prepared sample showed two desorption peaks whereas the calcined sample showed only one. In contrast to our results, Oyama [59] reported that $\mathrm{MoO}_{3}$ needles 
had a single desorption peak and two desorption peaks were found for powders. Generally, $\mathrm{NH}_{3}$ was also completely desorbed at temperatures below $350{ }^{\circ} \mathrm{C}$, indicating exclusively the presence of weak Lewis acidic sites. AHM_pH0_24h_calc was more acidic than the samples synthesized at $\mathrm{pH}=1$ and $\mathrm{pH}=2$ and featured a similar acidity as $\mathrm{MoO} 3 \cdot 2 \mathrm{H} 2 \mathrm{O} \_\mathrm{HNO} 3$ _calc. Using acetic acid led to less acidic materials compared to the sample synthesized from $\mathrm{MoO}_{3} \cdot 2 \mathrm{H}_{2} \mathrm{O}$ and $\mathrm{HNO}_{3}$.

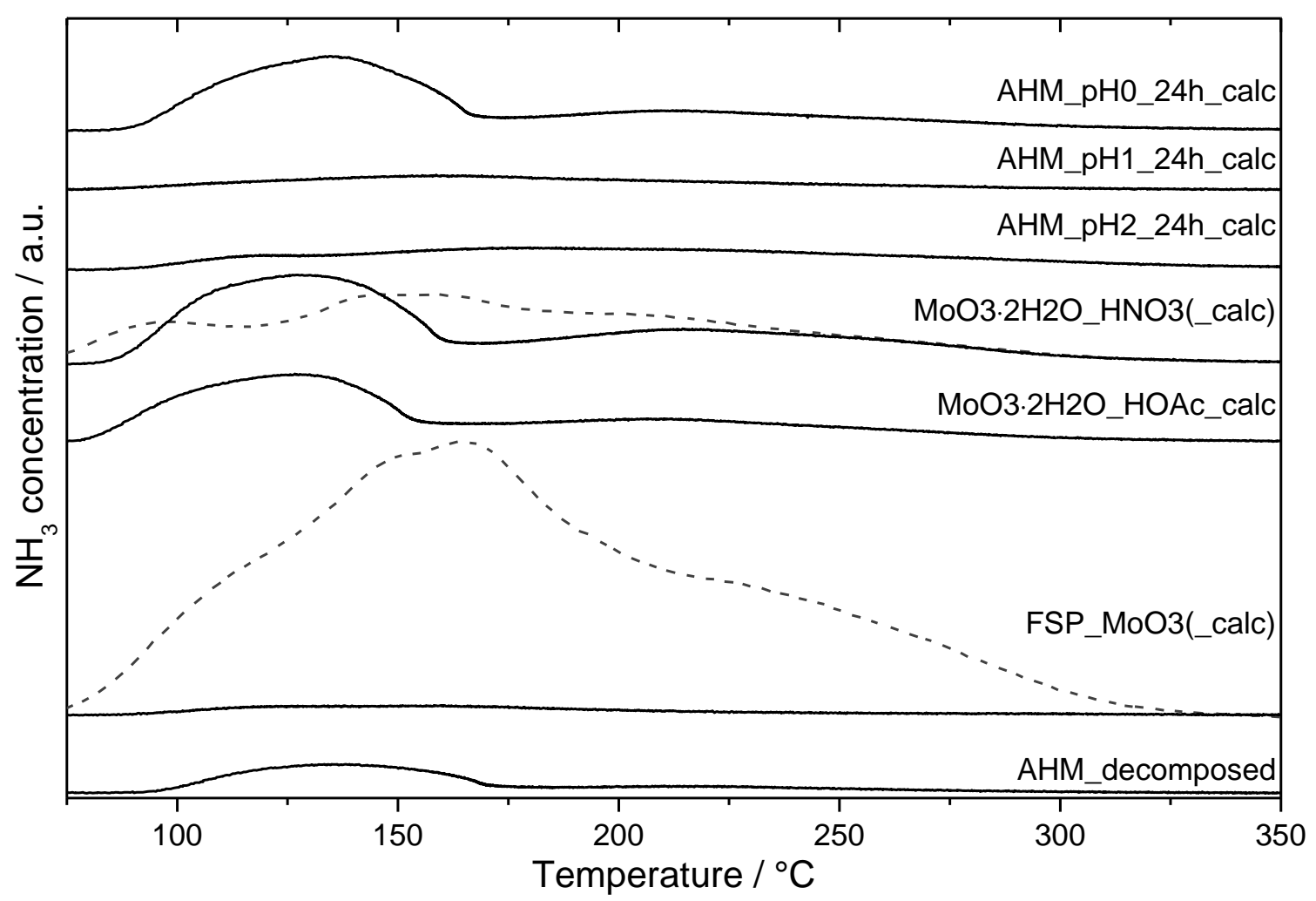

Figure 6: $\mathrm{NH}_{3}$-TPD of differently prepared $\alpha-\mathrm{MoO}_{3}\left(400 \mathrm{mg}\right.$ catalysts, $1000 \mathrm{ppm} \mathrm{NH} \mathrm{N}_{3}$ in $\mathrm{N}_{2}, 500 \mathrm{ml} / \mathrm{min}$ ). The dotted lines indicate the results for the as-prepared samples, full lines belong to calcined samples.

\subsection{Catalytic performance}

All samples, except the flame made sample FSP_MoO3_calc and the hydrothermally prepared sample MoO3·2H2O_HOAc_calc, revealed significant catalytic activity towards the partial and total oxidation of propylene under the applied conditions. Figure 7 demonstrates that all samples exhibited different catalytic activity and selectivity although they contained the same phase $\left(\alpha-\mathrm{MoO}_{3}\right)$. Thermally decomposed AHM showed low propylene conversion (maximum $5 \%$ at $50 \mathrm{Nml} / \mathrm{min}$ ), whereas the hydrothermally synthesized samples AHM_pH1_24h_calc and AHM_pH2_24h_calc reached a propylene conversion of 15\%. AHM_pH0_24h_calc converted more propylene $(10-40 \%)$ than the 
other catalysts. MoO3.2H2O_HNO3_calc converted between $8 \%$ and 30\% propylene under the applied conditions at $460{ }^{\circ} \mathrm{C}$. For the four most active catalysts in Figure 7 the selectivity to acrolein was higher than $15 \%$, the main undesired product for all samples was $\mathrm{CO}_{2}$, followed by $\mathrm{CO}$, acetaldehyde and propanal.

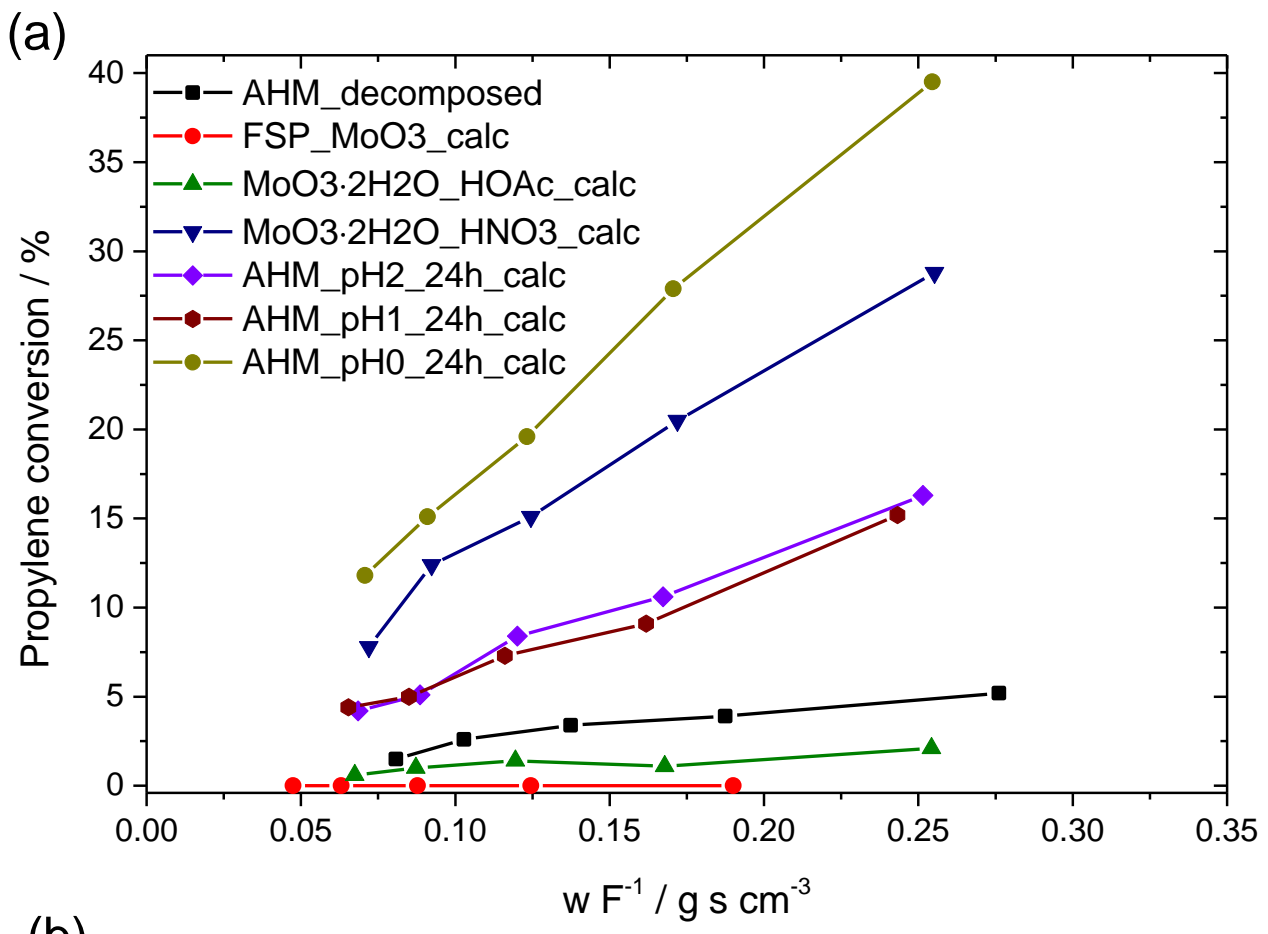

(b)

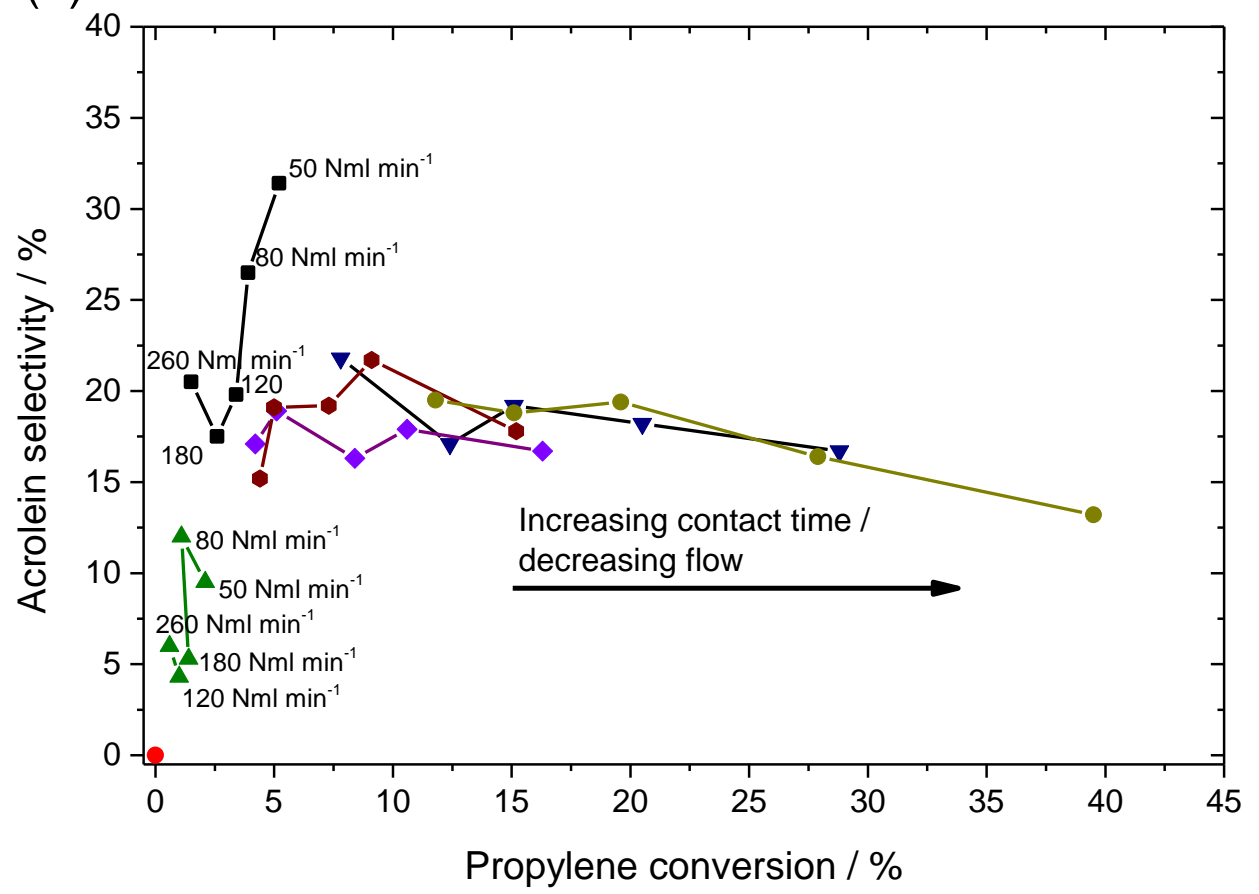

Figure 7: Catalytic performance of $\alpha-\mathrm{MoO}_{3}$ prepared by different methods and with various morphologies at $460{ }^{\circ} \mathrm{C}$ : propylene conversion as a function of contact time w/F, which was calculated at reaction temperature and pressure (a) and acrolein selectivity as a function of propylene conversion (b). $\left(\mathrm{C}_{3} \mathrm{H}_{6} / \mathrm{O}_{2} / \mathrm{N}_{2}=5 / 25 / 70\right.$, flows $50,80,120,180,260 \mathrm{Nml} / \mathrm{min}$, $500 \mathrm{mg}$ of catalyst; the lines are given as guide for the eye). 
The selectivity to acetaldehyde and propanal was about $1-9 \%$ and $0-2 \%$, respectively, where selectivity decreased with increasing propylene conversion. Also at low propylene conversion the selectivity to acrolein did not exceed 32\%. Comparison of the results in Figure 7 with Table 2 and the SEM images in Figure 2 reveals that the catalytic performance of the catalysts may be dependent on the morphology considering the low activity of FSP_MoO3_calc and AHM_decomposed. The two samples which exhibited the highest propylene conversion (AHM_pH0_24h_calc and MoO3 $2 \mathrm{H} 2 \mathrm{O} \_\mathrm{HNO} 3 \_$calc), both showed a rod-like morphology suggesting that rods were more active than the hexagonal prismatic particles (AHM_pH1_24h_calc) or particles with an irregular morphology (AHM_pH2_24h_calc or AHM_decomposed). However, the sample prepared by hydrothermal synthesis from $\mathrm{MoO}_{3} \cdot 2 \mathrm{H}_{2} \mathrm{O}$ and acetic acid also showed a rod-like morphology, but only negligible activity for propylene oxidation (Figure 7, maximum 2\% propylene conversion). Furthermore, the surface area and the acidity of MoO3-2H2O_HOAc_calc and AHM_pH0_24h_calc differed only slightly as well as the particle sizes. Generally, the surface area did not have a strong influence on the catalytic activity of $\alpha-\mathrm{MoO}_{3}$ : the flame made material exhibiting the highest surface area was completely inactive, whereas the hydrothermally synthesized samples from ammonium heptamolybdate at $\mathrm{pH}=1$ and $\mathrm{pH}=2$ showed a medium activity compared to the other tested samples in Figure 7, although their surface areas were low $\left(<1 \mathrm{~m}^{2} / \mathrm{g}\right)$.

\subsection{Structure-performance correlations}

To understand why the hydrothermally synthesized sample prepared from $\mathrm{MoO}_{3} \cdot 2 \mathrm{H}_{2} \mathrm{O}$ and acetic acid showed lower catalytic activity than the other rod-like materials and whether a change in phase or morphology during time on stream occurred, the catalysts were also characterized after application in propylene oxidation up to $520{ }^{\circ} \mathrm{C}$. According to X-ray diffraction measurements (Figure 8a) and Raman spectroscopy (Figure 8b) the phases did not change during the catalytic test reaction and after use all the samples still consisted of pure $\alpha-\mathrm{MoO}_{3}$. The relative intensities of the reflections in the diffraction pattern were hardly altered for the respective samples (cf. Figure 3 and Figure 8). Figure 9 shows the SEM images of these $\mathrm{MoO}_{3}$ samples after use in propylene oxidation and in Table 2 morphologies and particle sizes before and after use are compared. 

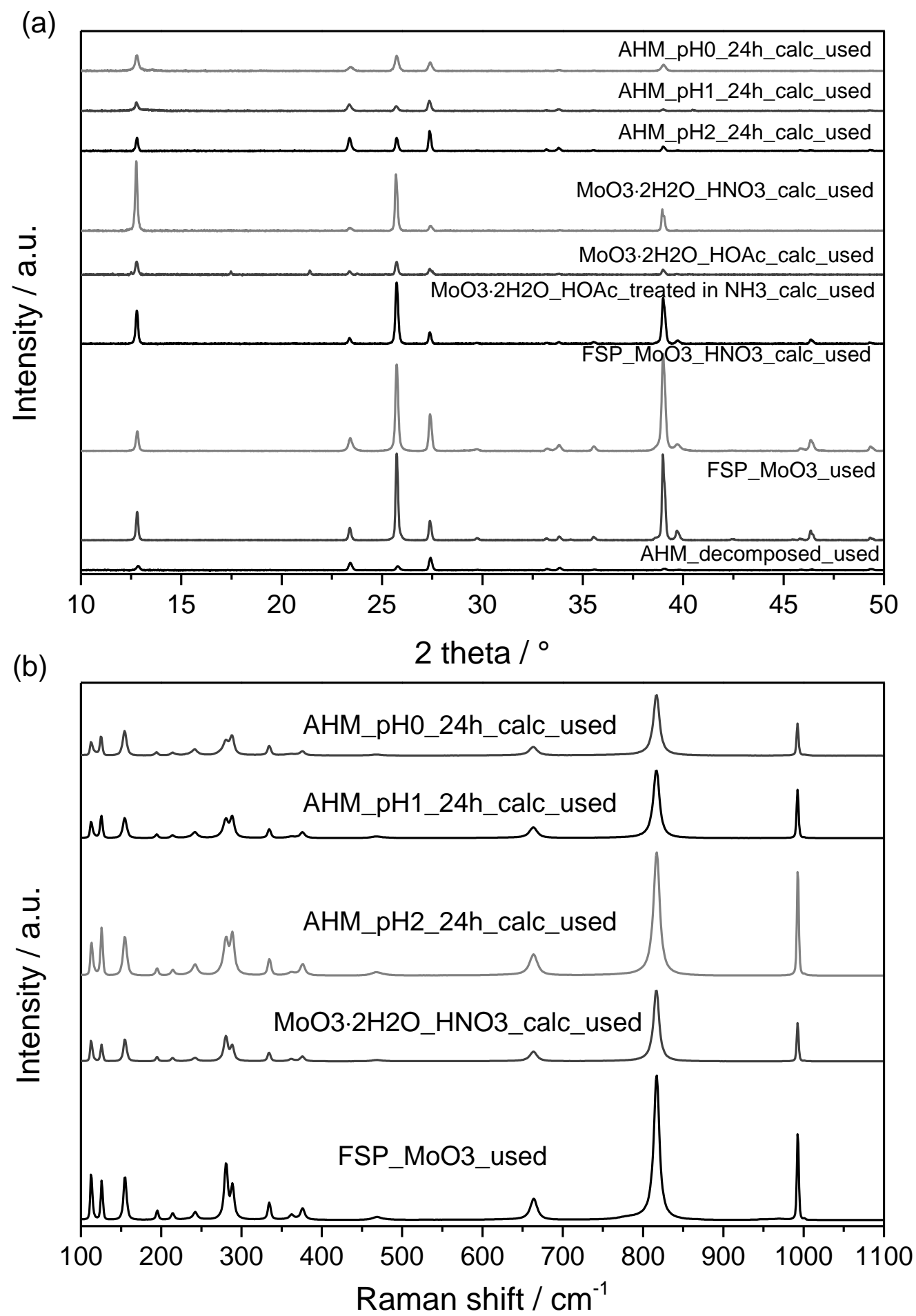

Figure 8: X-ray diffraction patterns (a) and Raman spectra (b) of differently prepared samples after the use in propylene oxidation at $420-520{ }^{\circ} \mathrm{C}$.

For AHM_decomposed the particles did not grow during time on stream and also the steps and edges on the surface of the plate-like particles are still visible in Figure 9a. The samples synthesized from $\mathrm{AHM}$ at $\mathrm{pH}=1$ and $\mathrm{pH}=2$, which exhibited a medium catalytic activity (5-16\% propylene conversion), both strongly changed their morphology and formed agglomerated plates during 
propylene oxidation (Figure 9d, e). This may be due to the fact that $\mathrm{MoO}_{3}$ was slightly reduced under reaction conditions forming sub-oxides [60] and - if catalytically active - also prone to structural changes. In fact, operando characterization studies on samples comparable to AHM_decomposed by Ressler et al. [60] showed that oxygen defects were formed under reaction conditions whereas $\alpha-\mathrm{MoO}_{3}$ remained the only phase according to PXRD. The particles formed for AHM_pH1_24h_calc_used were slightly larger (thicker and longer) than AHM_pH2_24h_calc_used. MoO3.2H2O_HOAc_calc, MoO3.2H2O_HNO3_calc and AHM_pH0_24h_calc all showed a rod-like morphology (Figure 1,

Figure 2b, d), but of different particle size.
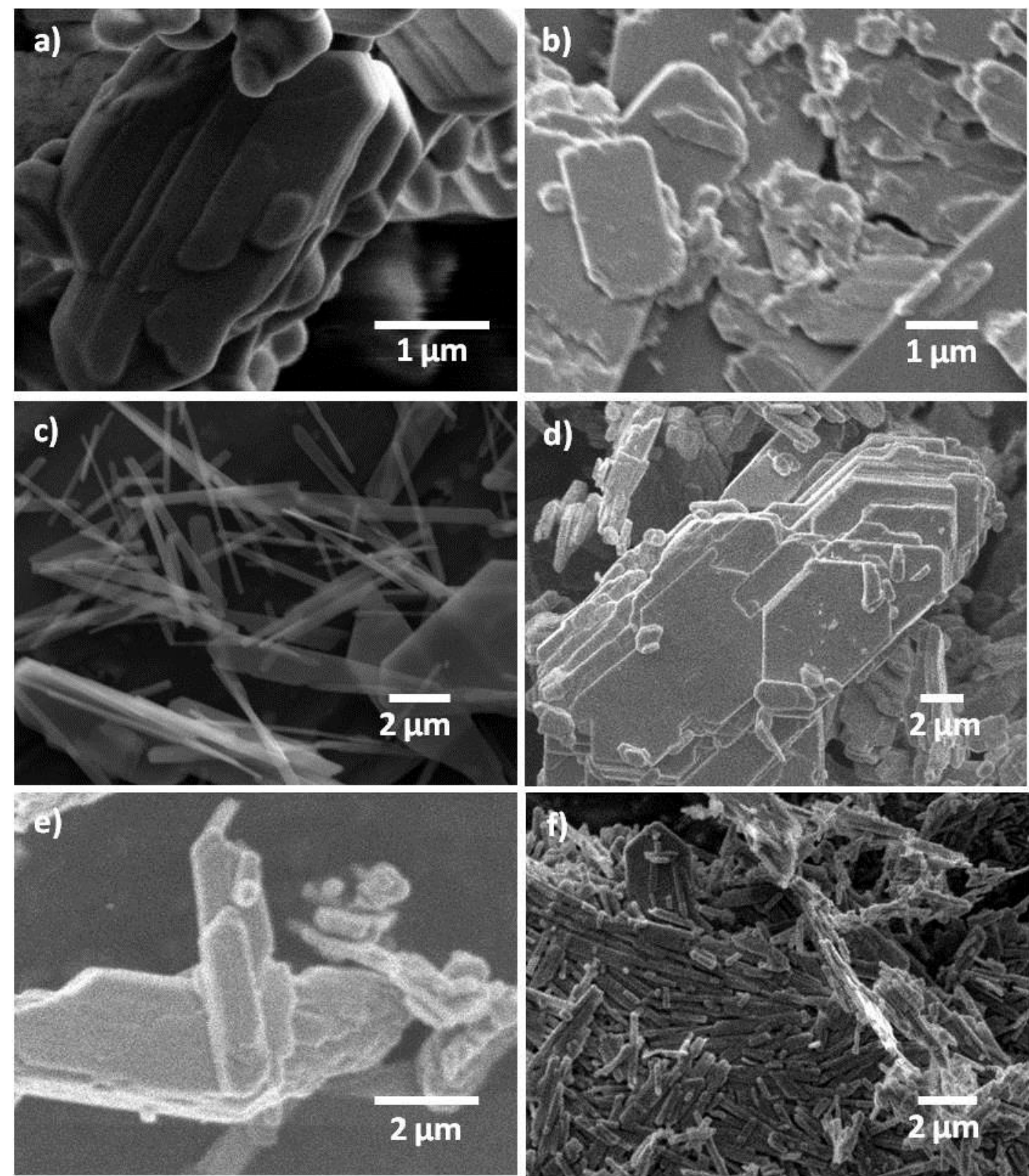

Figure 9: SEM images of different $\mathrm{MoO}_{3}$-samples after use in propylene oxidation at $420-520{ }^{\circ} \mathrm{C}$ a) AHM_decomposed_used, b) MoO3·2H2O_HOAc_calc_used, c) MoO3.2H2O_HNO3_calc_used, d) AHM_pH2_24h_calc_used, e) AHM_pH1_24h_calc_used and f) AHM_pH0_24h_calc_used. 
The particles of the sample prepared with acetic acid were thinner and shorter than the particles of MoO3·2H2O_HNO3_calc. MoO3·2H2O_HOAc_calc and AHM_pH0_24h_calc formed particles of similar size with a width of $200 \mathrm{~nm}$ and up to $2 \mu \mathrm{m}$ length (see Table 2). The aspect ratio of the particles of MoO3.2H2O_HOAc_calc changed during time on stream and plate-like particles were formed from the $\alpha-\mathrm{MoO}_{3}$ rods (Figure 9b), growing in the [001] and [100] direction. MoO3.2H2O_HNO3_calc partly preserved its morphology (Figure 9c) and only a few of the particles grew to plates, whereas AHM_pH0_24h_calc completely maintained its rod-like morphology (Figure 9f) slightly increasing in width and length (Table 2). Nitric acid seemed to stabilize the morphology of $\alpha-\mathrm{MoO}_{3}$ during catalytic application or heat treatment compared to acetic acid. In this way, a correlation of morphology of the samples after use (Figure 9) and the catalytic performance of the samples (Figure 7) can be established: $\alpha-\mathrm{MoO}_{3}$ reached the highest propylene conversion if its rod-like morphology was preserved during the activity measurement (AHM_pH0_24h_calc and MoO3·2H2O_HNO3_calc), while all the other samples had lower activity for propylene oxidation (Figure 7a). A morphology change from rod-like particles to plate-like particles led to lower propylene conversion. Although the rate was dependent on the average morphology throughout the catalytic activity measurements, the selectivity to acrolein was not influenced by the particle morphology (Figure 7b). Rods feature relatively large (100) and (010) facets whereas plates only contain large (010) facets. If the (010) facet was responsible for propylene activation, plates should be as active as rods. Our results support that propylene activation preferentially took place on the (100) facet, which means that propylene is adsorbed, hydrogen is abstracted and a surface complex of an allylic intermediate is formed [20, 61]. Brückman et al. [20] already found that the (100) facet was responsible for propylene activation, testing four $\mathrm{MoO}_{3}$ samples synthesized at different temperatures. So far, this has been demonstrated as well for two commercial samples with needle or plate crystals [40] and for $\mathrm{MoO}_{3}$ supported on silica [61]. In the present study a number of unsupported samples with similar thermal history were applied in propylene oxidation so that the influence of the temperature or the support on the relative activity of the various $\mathrm{MoO}_{3}$ catalysts can be excluded. Propylene activation ( $\alpha-\mathrm{H}$ abstraction and formation of an allyl intermediate) was observed to be the rate limiting step [61]. The (100) facets of $\alpha-\mathrm{MoO}_{3}$ consist of a double layer of oxygen atoms bound to 
molybdenum atoms, thus containing the highest Mo density. The $\mathrm{C}=\mathrm{C}$ double bond is attracted by these electrophilic centers and propylene is adsorbed on the superficial molybdenum [32]. Oxygen can be inserted in the activated propylene forming acrolein. If the adsorption of propylene is too strong, C$\mathrm{C}$ and/or $\mathrm{C}=\mathrm{C}$ bond cleavage and $\mathrm{CO}_{2}$ formation is favored. On the (100) plane each active Mo-site is surrounded by two active lattice oxygen atoms [39] so that the selectivity for the total combustion products was higher $(\sim 60 \%)$ than the selectivity for acrolein $(\sim 20 \%)$. The Mo-centers on the (100) facet act as Lewis-acid sites [37, 38], which were mostly preserved for AHM_pH0_24h_calc. $\mathrm{NH}_{3}-$ TPD measurements were not only performed on the fresh catalysts (Figure 6) but also on the used samples (see Figure 10). The number of $\mathrm{NH}_{3}$ adsorption sites for MoO3.2H2O_HOAc_calc, MoO3.2H2O_HNO3_calc and AHM_pH2_24h_calc decreased significantly after catalytic activity measurements (Table 1). Only AHM_pH0_24h_calc, which showed the best catalytic performance, retained relatively high acidity after its use in propylene oxidation.

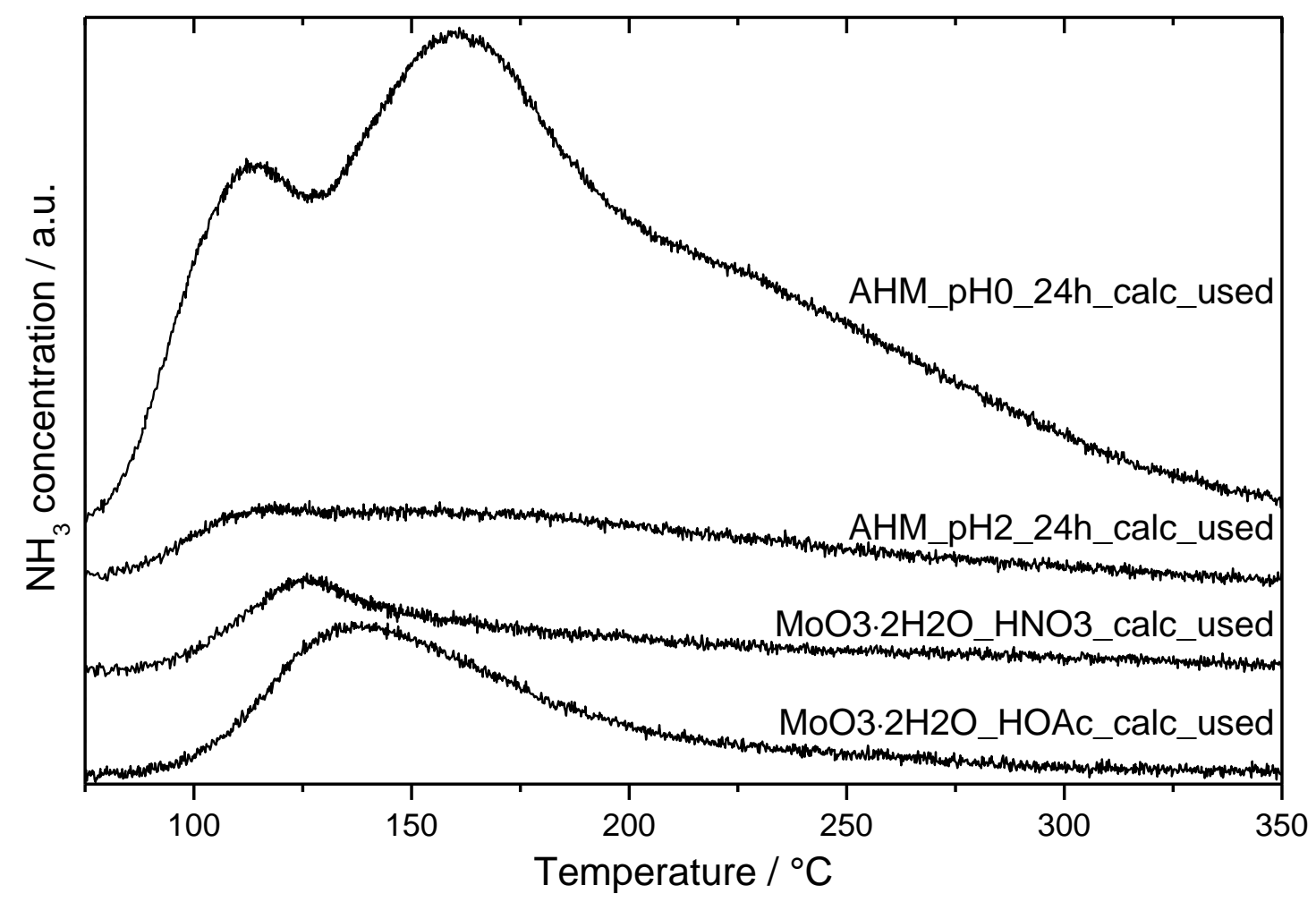

Figure 10: Temperature programmed desorption of ammonia of various $\mathrm{MoO}_{3}$ after application in propylene oxidation at temperatures up to $520^{\circ} \mathrm{C}$. 


\subsection{Influence of nitrogen incorporation on catalytic performance}

The results of the catalytic performance tests in Figure 7 also indicate that samples prepared using $\mathrm{HNO}_{3}$ were more active than the other samples, which may suggest that nitrogen incorporation into $\alpha$ $\mathrm{MoO}_{3}$ occurred during hydrothermal synthesis, thus increasing the catalytic activity for propylene oxidation. Therefore the hydrothermally prepared sample from $\mathrm{MoO}_{3} \cdot 2 \mathrm{H}_{2} \mathrm{O}$ and acetic acid, which did not contain nitrogen, was treated in ammonia. Additionally the flame made sample was treated hydrothermally in the presence of nitric acid. Quantitative nitrogen analysis of the samples implied that no nitrogen was incorporated from $\mathrm{HNO}_{3}$ into the samples during hydrothermal synthesis with nitric acid (cf. Table 1). For FSP_MoO3_HNO3_calc, AHM_pH0_24h_calc and MoO3.2H2O_HNO3_calc no nitrogen was detected, whereas $0.01 \mathrm{wt} \% \mathrm{~N}$ was found for AHM_pH1_24h_calc. In this case ammonium heptamolybdate could be the nitrogen source and thermal transformation of the hydrothermally prepared ammonium molybdenum oxide phase led to $\alpha$ $\mathrm{MoO}_{3}$ with remaining traces of nitrogen not detected by X-ray diffraction or Raman spectroscopy. MoO3.2H2O_HOAc treated in $\mathrm{NH}_{3}$ showed the highest concentration of nitrogen followed by thermally decomposed AHM (see Table 1). The measurements of the catalytic performance depicted in Figure 11 indicate that nitrogen incorporation into $\mathrm{MoO}_{3}$ slightly increased the catalytic activity for propylene oxidation. Treatment of $\mathrm{MoO} 3 \cdot 2 \mathrm{H} 2 \mathrm{O} \_\mathrm{HOAc} \_$calc in $\mathrm{NH}_{3}$ resulted in a nitrogen content of 0.049 wt. $\%$ and increased the propylene conversion from $2 \%$ to $6 \%$ at $50 \mathrm{Nml} / \mathrm{min}$ (Figure 11a) as well as the acrolein selectivity (Figure 11b). A similar experiment was performed by Kühn et al. [49], who treated commercial $\alpha-\mathrm{MoO}_{3}$ at $275{ }^{\circ} \mathrm{C}$ in ammonia resulting in a nitrogen content of $0.41 \mathrm{wt} . \%$. However, in this study commercial $\alpha-\mathrm{MoO}_{3}$ both before and after treatment in $\mathrm{NH}_{3}$ showed similar catalytic activity in propylene oxidation. Hydrothermal treatment of FSP_MoO3 in $\mathrm{HNO}_{3}$ also improved the catalytic activity (Figure 11) of $\alpha-\mathrm{MoO}_{3}$, although no nitrogen was detected in both samples and FSP_MoO3_HNO3 achieved similar propylene conversion as thermally decomposed AHM containing 0.024 wt.\% N.

Generally the activities displayed in Figure 11 were low and the values measured for propylene conversion below 5\% including the corresponding acrolein selectivity are relatively inaccurate. This implied only a minor enhancement of the catalytic performance as consequence of the nitrogen 
incorporation into $\alpha-\mathrm{MoO}_{3}$. Nitrogen incorporation could, thus, be excluded as the reason for the differing activities found for the distinct samples prepared by hydrothermal synthesis and flame spray pyrolysis.
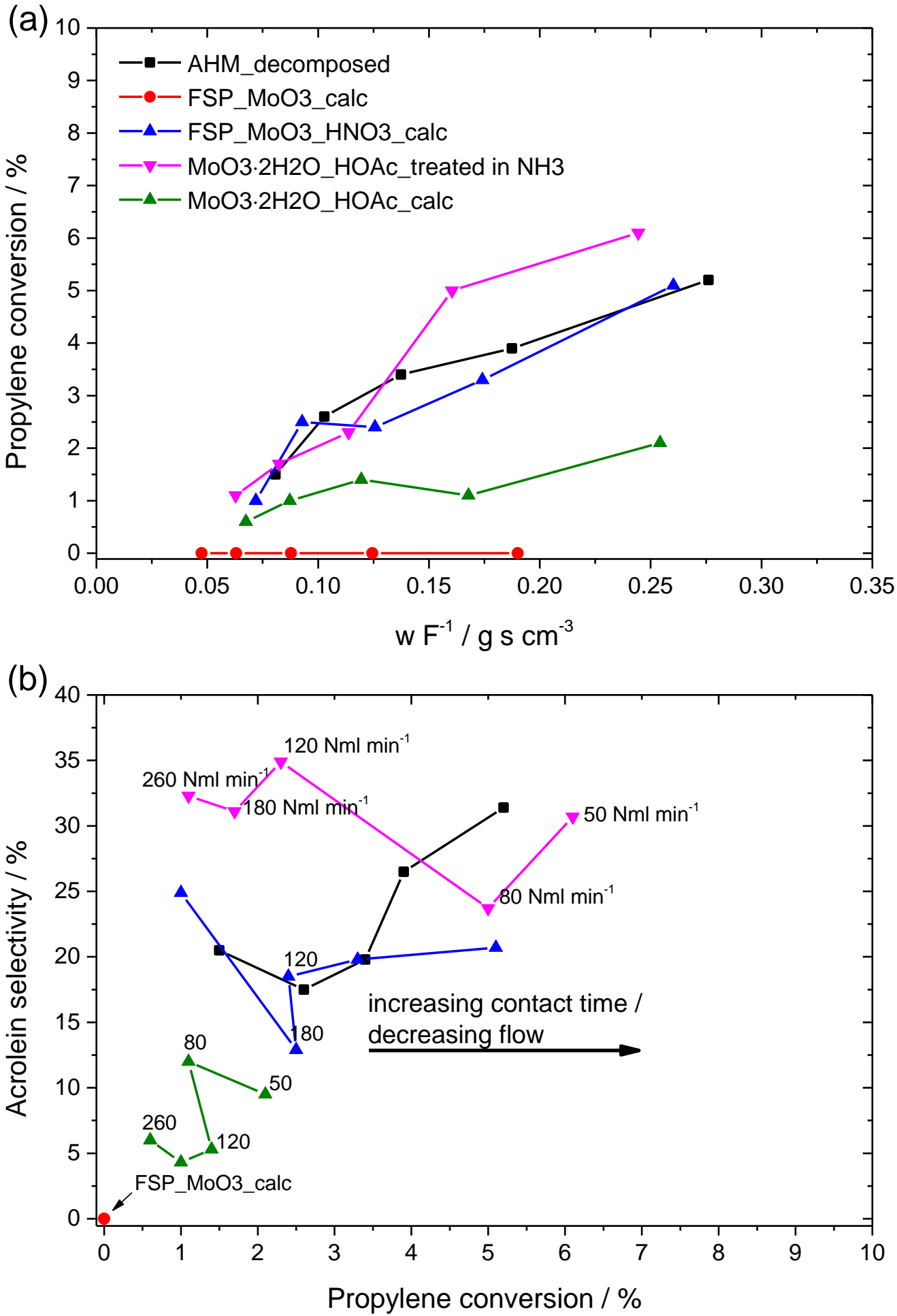

Figure 11: Propylene conversion as a function of contact time, w/F (a) and acrolein selectivity as a function of propylene conversion (b) for various samples to determine the influence of the nitrogen incorporation into $\mathrm{MoO}_{3}\left(\mathrm{C}_{3} \mathrm{H}_{6} / \mathrm{O}_{2} / \mathrm{N}_{2}=\right.$ $5 / 25 / 70$, flows $50,80,120,180,260 \mathrm{Nml} / \mathrm{min}, 460{ }^{\circ} \mathrm{C}, 500 \mathrm{mg}$ of catalyst; the lines are given as guide for the eye). 


\section{Conclusions}

Hydrothermal synthesis is a well suited method to analyze structure sensitivity of oxide materials due to the large variety of preparation parameters which can be adapted to obtain the desired product with designed properties. At the same time some parameters like temperature can be kept constant during the preparation of all samples. Hydrothermally prepared molybdenum trioxide $\left(\alpha-\mathrm{MoO}_{3}\right)$ is an excellent model system and can be applied for the investigation of the structure sensitivity in selective oxidation of propylene to acrolein. Variation of the morphology could be achieved by altering the $\mathrm{pH}$ value of the initial solution of ammonium heptamolybdate and nitric acid under hydrothermal conditions, due to the change of the polymolybdate species present in the solution at different $\mathrm{pH}$ values. After calcination all samples were transformed into pure $\alpha-\mathrm{MoO}_{3} \cdot \mathrm{MoO}_{3} \cdot 2 \mathrm{H}_{2} \mathrm{O}$ in the presence of acetic acid or nitric acid at $180{ }^{\circ} \mathrm{C}$ or ammonium heptamolybdate with nitric acid at $\mathrm{pH}=$ 0 directly resulted in $\alpha-\mathrm{MoO}_{3}$ rods in one step. The anisotropic growth of these $\mathrm{MoO}_{3}$ rods preferentially along the (010) direction was concluded from the different relative intensities of the characteristic reflections in the diffraction pattern and accordingly the bands in the Raman spectra. For comparison high surface area $\alpha-\mathrm{MoO}_{3}$ was successfully prepared by flame spray pyrolysis and platelike $\alpha-\mathrm{MoO}_{3}$ was obtained by thermal decomposition of AHM. These two samples were catalytically inactive and, obviously, rod-like structures with a relatively high amount of (100) facets seem to be important for the catalytic activity. This supports earlier studies showing that (100) facets are of decisive importance for the oxidation of propylene of molybdenum oxide surfaces.

However, the study demonstrates that additional constraints have to be considered: The morphology of the samples needs to be stabilized during the catalytic activity measurements, which was particularly observed for the samples prepared with nitric acid during synthesis. This preservation of the rod-like morphology during heat treatment and propylene oxidation resulted in high propylene conversion (10$40 \%$ conversion depending on the contact time). A morphology change to plates or stacked plates during propylene oxidation resulted in lower propylene conversion. This suggested that the (100) facet was responsible for propylene activation due to a high Mo density. The selectivity for the total combustion products was higher $(\sim 60 \%)$ than the selectivity for acrolein $(\sim 20 \%)$. The morphology of the samples did not have a significant effect on the selectivity to acrolein, but on the propylene 
conversion. Incorporation of nitrogen slightly improved the catalytic performance of $\alpha-\mathrm{MoO}_{3}$, but was not a decisive factor. Although $\mathrm{MoO}_{3}$ is an easy model system, correlation of the particle morphology and the catalytic activity and selectivity in propylene oxidation already requires a detailed characterization of the hydrothermally prepared materials before and after the catalytic test reaction. This may be further developed by extending the present study to operando characterization studies as well as more detailed (in situ) high resolution electron microscopy studies. Finally, the strategy needs to be extended to mixed transition molybdates which are technically more relevant and result in higher propylene conversion and improved selectivity to acrolein. Further studies along some of these lines are currently performed in our laboratories.

\section{Acknowledgments}

We thank the Danish Council for Strategic Research for financial support in the framework of the DSF proposal "Nanoparticle synthesis for catalysis". We gratefully acknowledge Dr. Thomas Bergfeldt at the Institute for Applied Materials in the Chemical Analysis group (IAM-AWP) at KIT for the quantitative nitrogen analysis. The European Synchrotron Radiation Facility (ESRF) in Grenoble is acknowledged for providing XAS beamtime at beamline BM01B. We thank Dr. Dmitry Doronkin for the XAS measurements and Dr. Wouter van Beek (ESRF) for help and support during the beamtime. The Center for Electron Nanoscopy (CEN) at DTU is acknowledged for providing microscopy time (SEM and TEM) and the help and support during the measurements.

\section{Supporting information}

Supplementary data (X-ray diffraction patterns, EXAFS spectra) associated with this article can be found, in the online version, at http://dx.doi.org/xx.xxxx. 


\section{References}

[1] Tana, M. Zhang, J. Li, H. Li, Y. Li, W. Shen, Catal. Today 148 (2009) 179-183.

[2] K.B. Zhou, X. Wang, X.M. Sun, Q. Peng, Y.D. Li, J. Catal. 229 (2005) 206-212.

[3] Y. Xu, H. Wang, Y. Yu, L. Tian, W. Zhao, B. Zhang, J. Phys. Chem. C 115 (2011) 1528815296.

[4] X. Mou, X. Wei, Y. Li, W. Shen, Cryst. Eng. Comm. 14 (2012) 5107-5120.

[5] X. Xie, Y. Li, Z.-Q. Liu, M. Haruta, W. Shen, Nature 458 (2009) 746-749.

[6] J.C. Védrine, G.J. Hutchings, C.J. Kiely, Catal. Today 217 (2013) 57-64.

[7] M. Gasior, T. Machej, J. Catal. 83 (1983) 472-476.

[8] J.C. Volta, J.M. Tatibouet, J. Catal. 93 (1985) 467-470.

[9] A. Baiker, D. Gasser, Z. Phys. Chem. Neue Fol. 149 (1986) 119-124.

[10] D. Koziej, M.D. Rossell, B. Ludi, A. Hintennach, P. Novak, J.-D. Grunwaldt, M. Niederberger, Small 7 (2011) 377-387.

[11] N. Pinna, M. Niederberger, Metal Oxide Nanoparticles in Organic Solvents: Synthesis, Formation, Assembly and Application. Springer-Verlag London Limited, London, 2009.

[12] G.R. Patzke, A. Michailovski, F. Krumeich, R. Nesper, J.-D. Grunwaldt, A. Baiker, Chem. Mater. 16 (2004) 1126-1134.

[13] C.N.R. Rao, A.K. Cheetham, J. Mater. Chem. 11 (2001) 2887-2894.

[14] M. Yoshimura, K. Byrappa, J. Mater. Sci. 43 (2008) 2085-2103.

[15] M.S. Whittingham, Curr. Opin. Solid. State Mater. Sci. 1 (1996) 227-232.

[16] K. Byrappa, M. Yoshimura, Handbook of hydrothermal technology. Noyes Publications, NJ, USA, 2001.

[17] M. Sadakane, N. Watanabe, T. Katou, Y. Nodasaka, W. Ueda, Angew. Chem.-Int. Ed. 46 (2007) 1493-1496.

[18] G. Mestl, Top. Catal. 38 (2006) 69-82.

[19] J. Haber, E. Lalik, Catal. Today 33 (1997) 119-137.

[20] K. Brückman, R. Grabowski, J. Haber, A. Mazurkiewicz, J. Słoczyński, T. Wiltowski, J. Catal. 104 (1987) 71-79.

[21] G. Mestl, B. Herzog, R. Schloegl, H. Knoezinger, Langmuir 11 (1995) 3027-3034.

[22] K. Schuh, W. Kleist, M. Høj, V. Trouillet, P. Beato, A.D. Jensen, G.R. Patzke, J.-D. Grunwaldt, Appl. Catal., A 482 (2014) 145-156.

[23] X.W. Lou, H.C. Zeng, Chem. Mater. 14 (2002) 4781-4789.

[24] T.A. Xia, Q. Li, X.D. Liu, J.A. Meng, X.Q. Cao, J. Phys. Chem. B 110 (2006) 2006-2012.

[25] K. Dewangan, S.S. Patil, D.S. Joag, M.A. More, N.S. Gajbhiye, J. Phys. Chem. C 114 (2010) 14710-14715.

[26] A. Phuruangrat, J.S. Chen, X.W. Lou, O. Yayapao, S. Thongtem, T. Thongtem, Appl. Phys. A Mater. Sci. Process. 107 (2012) 249-254.

[27] H. Sinaim, D.J. Ham, J.S. Lee, A. Phuruangrat, S. Thongtem, T. Thongtem, J. Alloys. Compd. 516 (2012) 172-178.

[28] A. Chithambararaj, A.C. Bose, J. Alloys. Compd. 509 (2011) 8105-8110.

[29] I.P. Olenkova, N.N. Chumachenko, L.M. Plyasova, D.V. Tarasova, E.N. Yurchenko, React. Kinet. Catal. Lett. 22 (1983) 339-343.

[30] N. Floquet, O. Bertrand, J.J. Heizmann, Oxid. Met. 37 (1992) 253-280. 
[31] J.C. Volta, B. Moraweck, J. Chem. Soc., Chem. Commun. (1980) 338-339.

[32] J.C. Volta, M. Forissier, F. Theobald, T.P. Pham, Faraday Discuss. 72 (1981) 225.

[33] J.M. Tatibouet, J.E. Germain, J. Catal. 72 (1981) 375-378.

[34] J.M. Tatibouet, C.R. Acad. Sci., Ser. II 297 (1983) 703.

[35] A. Baiker, P. Dollenmeier, A. Reller, J. Catal. 103 (1987) 394-398.

[36] R.A. Hernandez, U.S. Ozkan, Ind. Eng. Chem. Res. 29 (1990) 1454-1459.

[37] M. Abon, J. Massardier, B. Mingot, J.C. Volta, N. Floquet, O. Bertrand, J. Catal. 134 (1992) 542-548.

[38] B. Mingot, N. Floquet, O. Bertrand, M. Treilleux, J.J. Heizmann, J. Massardier, M. Abon, J. Catal. 118 (1989) 424-435.

[39] J. Ziolkowski, J. Catal. 80 (1983) 263-273.

[40] J. Haber, E. Serwicka, Polyhedron 5 (1986) 107-109.

[41] D.P. Debecker, B. Schimmoeller, M. Stoyanova, C. Poleunis, P. Bertrand, U. Rodemerck, E.M. Gaigneaux, J. Catal. 277 (2011) 154-163.

[42] W.J.M. van Well, M.T. Le, N.C. Schiodt, S. Hoste, P. Stoltze, J. Mol. Catal. A: Chem. 256 (2006) 1-8.

[43] J.J. Cruywagen, J.B.B. Heyns, S. Afr. J. Chem. 34 (1981) 118-120.

[44] M. Høj, K. Linde, T.K. Hansen, M. Brorson, A.D. Jensen, J.-D. Grunwaldt, Appl. Catal., A 397 (2011) 201-208.

[45] H.K. Kammler, L. Mädler, S.E. Pratsinis, Chem. Eng. Technol. 24 (2001) 583-596.

[46] L. Mädler, H.K. Kammler, R. Mueller, S.E. Pratsinis, J. Aerosol. Sci. 33 (2002) 369-389.

[47] T. Tani, L. Mädler, S.E. Pratsinis, J. Mater. Sci. 37 (2002) 4627-4632.

[48] W.Y. Teoh, R. Amal, L. Mädler, Nanoscale 2 (2010) 1324-1347.

[49] S. Kühn, P. Schmidt-Zhang, A.H.P. Hahn, M. Huber, M. Lerch, T. Ressler, Chem. Cent. J. 5 (2011).

[50] B. Ravel, M. Newville, J. Synchrotron Radiat. 12 (2005) 537-541.

[51] M. Høj, A.D. Jensen, J.-D. Grunwaldt, Appl. Catal., A 451 (2013) 207-215.

[52] J. Guo, P. Zavalij, M.S. Whittingham, J. Solid State Chem. 117 (1995) 323-332.

[53] L. Kihlborg, Ark. Kemi 21 (1963) 357.

[54] K. Dewangan, N.N. Sinha, P.K. Sharma, A.C. Pandey, N. Munichandraiah, N.S. Gajbhiye, Cryst. Eng. Comm. 13 (2011) 927-933.

[55] M. Dieterle, G. Weinberg, G. Mestl, Phys. Chem. Chem. Phys. 4 (2002) 812-821.

[56] A. Michailovski, J.-D. Grunwaldt, A. Baiker, R. Kiebach, W. Bensch, G.R. Patzke, Angew. Chem.-Int. Ed. 44 (2005) 5643-5647.

[57] G. Busca, E. Finocchio, G. Ramis, G. Ricchiardi, Catal. Today 32 (1996) 133-143.

[58] G.Z. Bian, L. Fan, Y.L. Fu, K. Fujimoto, Ind. Eng. Chem. Res. 37 (1998) 1736-1743.

[59] S.T. Oyama, Bull. Chem. Soc. Jpn. 61 (1988) 2585-2594.

[60] T. Ressler, J. Wienold, R.E. Jentoft, F. Girgsdies, Eur. J. Inorg. Chem. (2003) 301-312.

[61] R. Grabowski, T. Machej, A. Mazurkiewicz, J. Sloczynski, B. Pol. Acad. Sci. Chem. 35 (1987) 141. 